Electronic Supplementary Information for

\title{
Diastereoselective template synthesis on iron and uranium
}

Stephanie H. Carpenter, Brennan S. Billow, Aaron M. Tondreau*

Los Alamos National Laboratory, Los Alamos, New Mexico 87544, United States 


\section{Table of Contents}

1. Experimental Procedures

1.1 Materials

1.2 General Considerations

1.3 Synthesis of 2,6-bis-((trimethylsiloxy)(di-tert-butylphosphino)-methyl)-pyridine (1$\left.r / m,{ }^{(\mathrm{OTMS})} \mathrm{PNP}^{t \mathrm{Bu}}\right)$-rac:meso (63:37) mixture

1.4 Synthesis of ( $\left.{ }^{(\mathrm{OTMS})} \mathrm{PNP}^{t \mathrm{Bu}}\right) \mathrm{FeCl}_{2}$-rac:meso (63:37) mixture (2-r/m)

1.5 Separation of diastereoisomers: Isolation (95\%) of $C_{2}$ isomer of $\left({ }^{(\mathrm{OTMS})} \mathrm{PNP}^{t \mathrm{Bu}}\right) \mathrm{FeCl}_{2}$ (2-r)

1.6 Separation of diastereoisomers: Identification of $C_{s}$ isomer of $\left({ }^{(\mathrm{OTMS})} \mathrm{PNP}^{t \mathrm{Bu}}\right) \mathrm{FeCl}_{2}(\mathbf{2}-$ m)

1.7 Templated synthesis of $\mathbf{2}-\mathbf{m}$; high meso content (> 95\%) synthesis

1.8 Synthesis of a mixture $\left({ }^{\left({ }_{\mathrm{Bu}} \mathrm{P}\right)} \mathrm{ONO}\right) \mathrm{UCl}_{2}(\mathrm{dtbpy})(\mathbf{3}-\mathbf{m})$ and $\left({ }^{(\mathrm{OTMS})} \mathrm{PNO}^{\mathrm{tBu}}\right) \mathrm{UCl}_{3}(\mathrm{dtbpy})$

1.9 Synthesis of $\left({ }^{(t \mathrm{Bu} 2 \mathrm{P})} \mathrm{ONO}\right) \mathrm{UCl}_{2}$ (dtbpy) (3-m)

1.10 Discussion of steric pressure from tert-butyl groups

2. Supplementary Data

2.1 NMR data

$2.2 \mathrm{UV} / \mathrm{Vis}$ data

\subsection{Pictures of 3-m and 4-m}

3. Single Crystal X-ray Diffraction Data

3.1 CCDC Deposition

3.2 ( $\left.^{(\mathrm{OTMS})} \mathrm{PNP}^{t \mathrm{Bu}}\right) \mathrm{FeCl}_{2}$ (2-r)

3.3 ( $\left.{ }^{(\mathrm{OTMS})} \mathrm{PNP}^{t \mathrm{Bu}}\right) \mathrm{FeCl}_{2}$ (2-m)

$3.4\left({ }^{\left({ }^{(B u} 2 \mathrm{P}\right)} \mathrm{ONO}\right) \mathrm{UCl}_{2}$ (dtbpy) (3-m)

3.5 ( $\left.{ }^{(\mathrm{OTMS})} \mathrm{PNO}^{\mathrm{tBu}}\right) \mathrm{UCl}_{3}$ (dtbpy) (4-m)

4. References 


\section{Experimental Procedures}

Caution! Depleted uranium (primary isotope $\left.{ }^{238} \mathrm{U}\right)$ is a weak $\alpha$-emitter $(4.197 \mathrm{MeV})$ with a halflife of $4.47 \times 10^{9}$ years; only persons trained to handle such material should perform work and only in an adequately prepared laboratory setting.

1.1. Materials. The solvents THF, $n$-hexane, and pentane were dried on molecular sieves and shaved sodium before use; fluorobenzene was dried on molecular sieves before use. $\mathrm{C}_{6} \mathrm{D}_{6}$ was purchased from Cambridge Isotope Laboratories and dried over $4 \AA$ molecular sieves and sodium. The chemical $\mathrm{FeCl}_{2}$ was purchased from Sigma Aldrich and was used as received. $\mathrm{UCl}_{4}$ was synthesized from a previously reported procedure. ${ }^{1}$ 2,6-pyridine dicarboxaldehyde was purchased from Asta Tech (97\%) and was used as received for syntheses utilizing $\mathrm{UCl}_{4}$ or was used after recrystallization from fluorobenzene for syntheses utilizing $\mathrm{FeCl}_{2}$. The compound trimethylsilyl(di-tert-butyl)-phosphine was synthesized according to a published procedure. ${ }^{2}$

1.2. General Considerations. All air- and moisture-sensitive manipulations were carried out using standard Schlenk techniques or in an MBraun dry box containing a purified nitrogen (for iron syntheses) or a purified argon (for uranium syntheses) atmosphere. ${ }^{1} \mathrm{H},{ }^{13} \mathrm{C},{ }^{31} \mathrm{P}$, and ${ }^{29} \mathrm{Si} \mathrm{NMR}$ spectra were recorded on a Bruker Advance $400 \mathrm{MHz}$ spectrometer operating at $400.132 \mathrm{MHz}$, 100.627 MHz, $161.978 \mathrm{MHz}$, and 79.465 MHz, respectively. All ${ }^{1} \mathrm{H}$ and ${ }^{13} \mathrm{C}$ NMR chemical shifts are reported relative to $\mathrm{SiMe}_{4}$ using the ${ }^{1} \mathrm{H}$ (residual in the deuterated solvents) and ${ }^{13} \mathrm{C}$ chemical shifts of the solvent as a secondary standard. CHN analyses were conducted by Midwest Microlab, 7212 N. Shadeland Ave., Suite 110, Indianapolis, IN 46250. UV-vis/NIR spectra were collected at RT on a Cary 5000 UV-Vis-NIR spectrophotometer from Agilent Technologies.

Single crystals suitable for X-ray diffraction were coated with n-paratone (dried under reduced pressure overnight at $100{ }^{\circ} \mathrm{C}$ ) oil in a drybox, placed on a nylon loop and then transferred to the goniometer head of a Bruker AXS APEX II diffractometer equipped with a graphitemonochromatized molybdenum K $\alpha$ X-ray tube $(\lambda=0.71073 \AA)$ and an APEX II CCD detector, or to a Bruker D8 Quest equipped with a graphite-monochromatized molybdenum K $\alpha \mathrm{X}$-ray tube $(\lambda=$ $0.71073 \AA)$ and a CMOS detector, or on a Bruker D8 Quest using a Mo K $\alpha(\lambda=0.71073 \AA) \mathrm{I} \mu \mathrm{S}$ 3.0 Microfocus source X-ray generator. ${ }^{3}$ A hemisphere routine was used for data collection and determination of lattice constants. The space group was identified and the data were processed using the Bruker SAINT+ program and corrected for absorption using SADABS. ${ }^{4}$ The structures were solved using direct methods (SHELXS) completed by subsequent Fourier synthesis and refined by full-matrix least-squares procedures. ${ }^{5}$ Olex2 software was used as the graphical interface. ${ }^{6}$ Crystallographic data for all structures is available from the Cambridge Structural Database; see section 3.1 for CCDC deposition numbers

1.3. Synthesis of 2,6-bis-((trimethylsiloxy)(di-tert-butylphosphino)-methyl)-pyridine (1-r/m, (OTMS)PNPtBu)-rac:meso (63:37) mixture. A $50 \mathrm{~mL}$ round bottom flask was loaded with a stir bar, $0.460 \mathrm{~g}(3.404 \mathrm{mmol})$ of 2,6-pyridine dicarboxaldehyde, and $30 \mathrm{~mL}$ of diethyl ether. The reaction vessel was cooled to $-30{ }^{\circ} \mathrm{C}$, and trimethylsilyl-(di-tert-butyl)-phosphine $(1.490 \mathrm{~g}, 6.820 \mathrm{mmol}$, very slight excess for 2.0 equivalents) was added dropwise over the course of a minute. The reaction was allowed to stir for $16 \mathrm{hrs,} \mathrm{at} \mathrm{which} \mathrm{time} \mathrm{it} \mathrm{was} \mathrm{filtered} \mathrm{through} \mathrm{a} \mathrm{medium} \mathrm{porosity} \mathrm{frit}$ to remove a small quantity of insoluble tan material, and the volatiles were removed under reduced 
pressure until reaching a constant mass (1.850 g, 95\% of expected mass). The ligand was used crude, but by ${ }^{1} \mathrm{H}$ NMR integration (ligand:free phosphine) was $>90 \%$ pure. The 63:37 rac:meso mixture did not change when the reaction was performed colder, likely as a result of the P-Si addition not proceeding until the reaction mixture warmed up to a similar temperature. Analysis for $\mathrm{C}_{29} \mathrm{H}_{59} \mathrm{~N}_{1} \mathrm{O}_{2} \mathrm{P}_{2} \mathrm{Si}_{2} .{ }^{1} \mathrm{H}$ NMR $\left(\mathrm{C}_{6} \mathrm{D}_{6}, 23{ }^{\circ} \mathrm{C}\right): 7.39(\mathrm{~d}, 2 \mathrm{H}, \mathrm{J}=8.0 \mathrm{~Hz}, m-\mathrm{Py} \underline{\mathrm{H}}$, meso $), 7.36(\mathrm{~d}, 2 \mathrm{H}$, $\mathrm{J}=7.7 \mathrm{~Hz}, m-\mathrm{Py} \underline{\mathrm{H}}, r a c), 7.16(\mathrm{t}, 1 \mathrm{H}, \mathrm{J}=7.8 \mathrm{~Hz}, p-\mathrm{Py} \underline{\mathrm{H}}, r a c), 7.15(\mathrm{t}, 1 \mathrm{H}, \mathrm{J}=7.8 \mathrm{~Hz}, p$-Py,

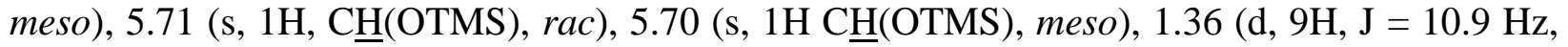
$\underline{t \mathrm{BuP}}, r a c), 1.34(\mathrm{~d}, 9 \mathrm{H}, \mathrm{J}=10.9 \mathrm{~Hz}, \underline{t \mathrm{BuP}}$, meso $), 1.29(\mathrm{~d}, 9 \mathrm{H}, \mathrm{J}=10.3 \mathrm{~Hz}, \underline{t \mathrm{BuP}}$, meso $), 1.27$ (d,

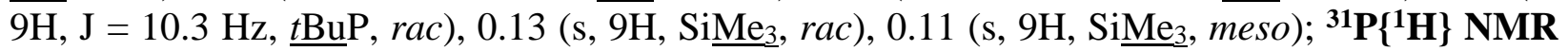
$\left.\left(\mathrm{C}_{6} \mathrm{D}_{6}\right), 23{ }^{\circ} \mathrm{C}\right): 52.2$ (rac), 50.0 (meso); ${ }^{13} \mathbf{C}\left\{{ }^{1} \mathbf{H}\right\}$ NMR $\left(\mathrm{C}_{6} \mathrm{D}_{6}, 23{ }^{\circ} \mathrm{C}\right): 163.5$ (s, rac), 163.4 (s, meso), 135.3 (s, meso), 135.4 (s, rac), 120.3 (dd, J = 7, $2 \mathrm{~Hz}$, meso), 119.7 (dd, J = 6, $2 \mathrm{~Hz}$, rac), 78.0 (d, J = 34 Hz, meso), 77.6 (d, J = $35 \mathrm{~Hz}, r a c), 34.0$ (d, J = $30 \mathrm{~Hz}, r a c), 33.9$ (d, J = $30 \mathrm{~Hz}$, meso), 32.3 (d, J = 27 Hz, rac), 32.3 (d, J = 26, meso), 31.2 (d, J = $13 \mathrm{~Hz}, r a c), 31.1$ (d, J = 14 Hz, meso $), 13.7$ (d, J = $13 \mathrm{~Hz}$, meso $), 13.6(\mathrm{~d}, \mathrm{~J}=14 \mathrm{~Hz}$, rac $), 0.6(\mathrm{~s}$, rac + meso $) ;{ }^{29} \mathbf{S i}\left\{{ }^{1} \mathbf{H}\right\} \mathbf{~ N M R}$ $\left(\mathrm{C}_{6} \mathrm{D}_{6}, 23^{\circ} \mathrm{C}\right.$ ), 18.30 (rac), 18.22 (meso).

1.4. Synthesis of $\left.{ }^{\left({ }^{(O T M S}\right)} \mathrm{PNP}^{t \mathrm{Bu}}\right) \mathrm{FeCl}_{2}$-rac:meso (63:37) mixture (2-r/m). A $100 \mathrm{~mL}$ round bottom flask was charged with $0.222 \mathrm{~g}(1.75 \mathrm{mmol})$ of $\mathrm{FeCl}_{2}$ in an inert atmosphere drybox and stirred with $35 \mathrm{~mL}$ of THF. To this slurry was added $1.00 \mathrm{~g}(1.75 \mathrm{mmol})$ of ${ }^{(\mathrm{OTMS})}{ }^{\mathrm{PNP}}{ }^{t \mathrm{Bu}}$ resulting in dissolution of the iron starting material and a color change to yellow/orange. Following a 16-hr reaction period, the solution was filtered through a plug of Celite, which was washed with $10 \mathrm{~mL}$ THF and the volatiles were removed under reduced pressure. The dark yellow sticky solid was mobilized in $50 \mathrm{~mL}$ of $n$-hexane and the dark yellow powder was collected on a glass frit and held under reduced pressure to a constant mass (yield $1.100 \mathrm{~g}, 90 \%$ ) identified as ${ }^{(\mathrm{OTMS})} \mathrm{PNP}^{t \mathrm{Bu}^{2}} \mathrm{FeCl}_{2}$ (2-r/m). Analysis for $\mathrm{C}_{29} \mathrm{H}_{59} \mathrm{Cl}_{2} \mathrm{Fe}_{1} \mathrm{~N}_{1} \mathrm{P}_{2} \mathrm{O}_{2} \mathrm{Si}_{2}$. Calculated: $\mathrm{C}=49.86 \%, \mathrm{H}=8.51 \%, \mathrm{~N}=2.00 \%$. Found: $\mathrm{C}=50.10 \%, \mathrm{H}=8.38 \%, \mathrm{~N}=2.07 \% .{ }^{1} \mathbf{H} \mathbf{N M R}\left(\mathrm{C}_{6} \mathrm{D}_{6}, 23{ }^{\circ} \mathrm{C}\right): 62.00(2 \mathrm{H}, \mathrm{J}=28 \mathrm{~Hz}$,

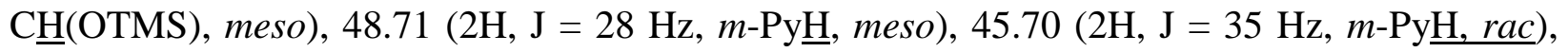
$23.37(18 \mathrm{H}, \mathrm{J}=127 \mathrm{~Hz}, \underline{\mathrm{BuP}}, r a c), 11.48(18 \mathrm{H}, \mathrm{J}=111 \mathrm{~Hz}, \underline{t \mathrm{BuP}}, \mathrm{rac}), 4.10(18 \mathrm{H}, \mathrm{J}=17 \mathrm{~Hz}$, $\mathrm{OSiMe}_{3}$, meso $), 3.75(18 \mathrm{H}, \mathrm{J}=138 \mathrm{~Hz}, \underline{t \mathrm{BuP}}$, meso $), 1.49(18 \mathrm{H}, \mathrm{J}=113 \mathrm{~Hz}, \underline{t \mathrm{BuP}}$, meso $),-2.27$ $\left(18 \mathrm{H}, \mathrm{J}=11 \mathrm{~Hz}, \mathrm{OSiMe}_{3}, r a c\right),-12.99(2 \mathrm{H}, \mathrm{J}=150 \mathrm{~Hz}, \mathrm{C} \underline{\mathrm{H}}(\mathrm{OTMS}), r a c),-16.16(2 \mathrm{H}, \mathrm{J}=23 \mathrm{~Hz}$, $p$-Py్, rac $),-16.38(2 \mathrm{H}, \mathrm{J}=24 \mathrm{~Hz}, p$-Py, meso $)$. An Evans method obtained in $\mathrm{C}_{6} \mathrm{D}_{6}$ of $2-r / m$ returned a magnetic moment of $4.66 \mu_{\mathrm{B}}$, close to the spin-only value of $4.90 \mu_{\mathrm{B}}$ expected for a high-spin ferrous center $\left(S_{\mathrm{Fe}}=2\right){ }^{7-8}$

\subsection{Separation of diastereoisomers: Isolation $(95 \%)$ of $C_{2}(\mathrm{rac})$ isomer of $\left({ }^{(\mathrm{OTMS})} \mathrm{PNP}^{t \mathrm{Bu}}\right) \mathrm{FeCl}_{2}$} (2-r). A $0.240 \mathrm{~g}$ measure of isolated $\mathbf{2}-\mathbf{r} / \mathbf{m}$ was dissolved in $3 \mathrm{~mL}$ of fluorobenzene and filtered through Celite into a $20 \mathrm{~mL}$ scintillation vial. The Celite was rinsed through with $0.5 \mathrm{~mL}$ of fluorobenzene. A $3 \mathrm{~mL}$ vial was filled with pentane and placed within the larger vial that was then capped and the pentane was allowed to vapor-diffuse into the fluorobenzene solution over the course of 8 hours, at which time the small vial was refilled with pentane, and the diffusion was allowed to continue overnight. Orange blocks grew over this time which were isolated $(0.053 \mathrm{~g}$, $22 \%$ from starting $\mathbf{2 - r} / \mathbf{m}$ ). The mother liquor was carefully removed and the orange blocks were analyzed by ${ }^{1} \mathrm{H}$ NMR and single crystal X-ray diffraction, allowing for the assignment as the $C_{2}$ isomer 2-r. Analysis for $r a c \mathrm{C}_{29} \mathrm{H}_{59} \mathrm{Cl}_{2} \mathrm{Fe}_{1} \mathrm{~N}_{1} \mathrm{P}_{2} \mathrm{O}_{2} \mathrm{Si}_{2} .{ }^{1} \mathbf{H} \mathbf{N M R}\left(\mathrm{C}_{6} \mathrm{D}_{6}, 23{ }^{\circ} \mathrm{C}\right): 45.70(2 \mathrm{H}, \mathrm{J}=35$ $\mathrm{Hz}, m-\mathrm{Py} \underline{\mathrm{H}}), 23.37(18 \mathrm{H}, \mathrm{J}=127 \mathrm{~Hz}, \underline{t \mathrm{BuP}}), 11.48(18 \mathrm{H}, \mathrm{J}=111 \mathrm{~Hz}, \underline{t \mathrm{BuP}}),-2.27(18 \mathrm{H}, \mathrm{J}=11$ 
$\left.\mathrm{Hz}, \mathrm{OSiMe}_{3}\right),-12.99(2 \mathrm{H}, \mathrm{J}=150 \mathrm{~Hz}, \mathrm{C} \underline{\mathrm{H}}(\mathrm{OTMS})),-16.16(2 \mathrm{H}, \mathrm{J}=23 \mathrm{~Hz}, p-\mathrm{Py} \underline{\mathrm{H}}),-16.38(2 \mathrm{H}, \mathrm{J}$ $=24 \mathrm{~Hz}, p$-Py$)$.

1.6. Separation of diastereoisomers: Identification of $C_{\mathrm{s}}(\mathrm{meso})$ isomer of $\left({ }^{(\mathrm{OTMS})} \mathrm{PNP}^{t \mathrm{Bu}}\right) \mathrm{FeCl}_{2}$ (2-m). The separated mother liquor from 2-rac isolation was cooled to $-30{ }^{\circ} \mathrm{C}$ and allowed to sit undisturbed for 64 hours, over which time yellow plates grew in starburst clusters. These plates were separated from the mother liquor and analyzed via ${ }^{1} \mathrm{H}$ NMR and single crystal X-ray diffraction, allowing for the assignment as the $C_{\mathrm{s}}$ isomer 2-m. This method did not provide stereopure material.

1.7. Templated synthesis of $2-m$; high meso content (> 95\%) synthesis. A $20 \mathrm{~mL}$ scintillation vial was charged with 2,6-pyridine dicarboxaldehyde ( $0.250 \mathrm{~g}, 1.850 \mathrm{mmol}), \mathrm{FeCl}_{2}(0.234 \mathrm{~g}, 1.850$ $\mathrm{mmol}$ ), and a stir bar. While stirring the solids, $12 \mathrm{~mL}$ of fluorobenzene was added and the solution was stirred for 16 hours in such a way as to disrupt solid aggregates that would form to encourage complete consumption of the starting materials. The solid material at that time was dark in color, and formed a slurry while stirring. To this stirring slurry was added dropwise, over the course of 10 minutes, $0.810 \mathrm{~g}$ (2 equiv., $3.705 \mathrm{mmol}$ ) of trimethylsilyl-(di-tert-butyl)-phosphine. The solution became yellow over the course of addition with concomitant dissolution of the dark iron material in the vial. After the addition, the reaction was stirred for 16 hours, the solution was filtered over Celite, and the volatiles were removed. The yellow powder remaining was analyzed via ${ }^{1} \mathrm{H}$ NMR and showed highly enriched 2-m. The yield was $1.110 \mathrm{~g}$ (86\% yield). Recrystallization was performed via a pentane vapor diffusion into a concentrated benzene solution of 2- $\boldsymbol{m}$ overnight to give $0.944 \mathrm{~g}(73 \%)$ of $\mathbf{2}-\boldsymbol{m}$ in high diastereo-purity. Analysis for meso $\mathrm{C}_{29} \mathrm{H}_{59} \mathrm{Cl}_{2} \mathrm{Fe}_{1} \mathrm{~N}_{1} \mathrm{P}_{2} \mathrm{O}_{2} \mathrm{Si}_{2}$. Calculated: $\mathrm{C}=49.86 \%, \mathrm{H}=8.51 \%, \mathrm{~N}=2.00 \%$. Found: $\mathrm{C}=50.22 \%, \mathrm{H}$ $=8.96 \%, \mathrm{~N}=2.36 \% .{ }^{1} \mathrm{H}$ NMR $\left(\mathrm{C}_{6} \mathrm{D}_{6}, 23{ }^{\circ} \mathrm{C}\right) 62.00(2 \mathrm{H}, \mathrm{J}=28 \mathrm{~Hz}, \mathrm{CH}(\mathrm{OTMS})), 48.71(2 \mathrm{H}, \mathrm{J}=$ $28 \mathrm{~Hz}, m-\mathrm{Py} \underline{\mathrm{H}}), 4.10\left(18 \mathrm{H}, \mathrm{J}=17 \mathrm{~Hz}, \mathrm{OSiMe}_{3}\right), 3.75(18 \mathrm{H}, \mathrm{J}=138 \mathrm{~Hz}, \underline{t \mathrm{BuP}}), 1.49(18 \mathrm{H}, \mathrm{J}=113$ $\mathrm{Hz}, \underline{t \mathrm{BuP}}),-16.38(2 \mathrm{H}, \mathrm{J}=24 \mathrm{~Hz}, p-\mathrm{Py} \underline{\mathrm{H}})$.

1.8. Synthesis of a mixture of $\left({ }^{(t \mathrm{Bu} 2 \mathrm{P})} \mathrm{ONO}\right) \mathrm{UCl}_{2}(\mathrm{dtbpy})(3-m)$ and $\left({ }^{(\mathrm{OTMS})} \mathrm{PNO}^{\mathrm{tBu}}\right) \mathrm{UCl}_{3}(\mathrm{dtbpy})$ (4-m). A $20 \mathrm{~mL}$ scintillation vial was charged with 2,6-pyridine dicarboxaldehyde $(17 \mathrm{mg}, 0.13$ mmol), $\mathrm{UCl}_{4}$ (50 mg, $0.13 \mathrm{mmol}$ ), 4,4'-di-tert-butyl-2,2'-dipyridyl (dtbpy, $35 \mathrm{mg}, 0.13 \mathrm{mmol}$ ), and a stir bar. The solids were dissolved in $1 \mathrm{~mL}$ THF and the resulting solution was bright green after mixing for $5 \mathrm{~min}$. To this solution was added $60 \mathrm{mg}$ trimethylsilyl-(di-tert-butyl)-phosphine ( $0.27 \mathrm{mmol}, 2.08$ equiv). The green solution became dark olive-brown, and the resulting solution was allowed to mix briefly. The volatiles were removed, resulting in a tacky, dark solid. This solid was dissolved in $1 \mathrm{~mL}$ of fluorobenzene and stored at $-30{ }^{\circ} \mathrm{C}$ until red needles were observed and determined to be 3-meso by single crystal X-ray diffraction. Analysis for $\mathrm{UC}_{41} \mathrm{H}_{65} \mathrm{P}_{2} \mathrm{~N}_{3} \mathrm{O}_{2} \mathrm{Cl}_{2}$. Calculated: $\mathrm{C}=49.10 \%, \mathrm{H}=6.53 \%, \mathrm{~N}=4.19 \%$. Found: $\mathrm{C}=49.51 \%, \mathrm{H}=6.55 \%, \mathrm{~N}=3.92 \% .{ }^{1} \mathrm{H}$ NMR $\left(\mathrm{C}_{6} \mathrm{D}_{6}, 23{ }^{\circ} \mathrm{C}\right): 67.16,24.30,22.44,5.54,4.18,3.51$ 1.36, 1.11, 1.09, 0.97, 0.24, -1.72, -2.97, -7.08, -7.88, -12.11; ${ }^{31} \mathbf{P}\{\mathbf{H}\} \mathbf{~ N M R}\left(\mathrm{C}_{6} \mathrm{D}_{6}, 23{ }^{\circ} \mathrm{C}\right)$ : 86.01. Magnetic susceptibility studies utilizing Evans method NMR revealed a magnetic moment of $2.33 \mu_{\mathrm{B}}$, which is consistent with previously reported U(IV) complexes. ${ }^{9-10} 24 \%$ crystalline yield. Green solid was observed concomitantly, but was not crystalline. Increasing the concentration of this reaction from $130 \mathrm{mM}$ to $670 \mathrm{mM} \mathrm{WRT}$ $\mathrm{UCl}_{4}$, allowed for the isolation and characterization of the green material by single crystal X-ray diffraction. This green material was determined to be 4-m. Analysis for $\mathrm{UC}_{44} \mathrm{H}_{74} \mathrm{P}_{2} \mathrm{~N}_{3} \mathrm{O}_{2} \mathrm{SiCl}_{3}$. Calculated: $\mathrm{C}=47.55 \%, \mathrm{H}=6.71 \%, \mathrm{~N}=3.72 \%$. Found: $\mathrm{C}=45.76 \%, \mathrm{H}=5.42 \%, \mathrm{~N}=4.51 \% .{ }^{1} \mathbf{H}$ 
$\operatorname{NMR}\left(\mathrm{C}_{6} \mathrm{D}_{6}, 23^{\circ} \mathrm{C}\right): 46.70,37.72,29.19,27.42,24.20,23.99,15.08,6.89,6.81,6.78,3.40,1.37$, $1.29,1.19,1.15,1.05,0.88,0.14,-2.90,-4.29,-6.97,-7.76,-11.14,-12.04,-18.01,-19.25,-19.54$, -20.67, -90.10, -95.31, -97.22. Magnetic susceptibility studies utilizing Evans method NMR revealed a low magnetic moment of $1.48 \mu_{\mathrm{B}}$. 20\% crystalline yield was achieved via physical separation of the crystal mixture.

1.9. Synthesis of $\left.{ }^{\left({ }^{(t B u 2 P}\right)} \mathrm{ONO}\right) \mathbf{U C l}_{2}(\mathbf{d t b p y})(\mathbf{3 - m})$. To a $20 \mathrm{~mL}$ scintillation vial was added $2,6-$ pyridine dicarboxaldehyde ( $34 \mathrm{mg}, 0.26 \mathrm{mmol}), \mathrm{UCl}_{4}(100 \mathrm{mg}, 0.26 \mathrm{mmol}$ ), and a stir bar. THF $(1 \mathrm{~mL})$ was added, resulting in dark insoluble material. This solid material was allowed to stir in THF for $1 \mathrm{hr}$ at room temperature. After this time, trimethylsilyl-(di-tert-butyl)-phosphine (118 $\mathrm{mg}, 0.54$ equiv, 2.08 equiv) was added at once resulting in a vibrant green solution. The green solution was allowed to mix at room temperature for $1 \mathrm{hr}$. The volatiles were then removed under vacuum, and dtbpy $(70 \mathrm{mg}, 0.26 \mathrm{mmol})$ was added to the solid. Fluorobenzene $(1 \mathrm{~mL})$ was used to dissolve the solids, and immediate color change to red upon the addition of fluorobenzene was observed. This solution was allowed to mix at room temperature for $15 \mathrm{~min}$ prior to storing the red solution at $-30{ }^{\circ} \mathrm{C}$. Red crystalline needles formed the next day in $67 \%$ crystalline yield, and were confirmed to be 3- $\boldsymbol{m}$ by single crystal X-ray diffraction. 
1.10. Discussion of steric pressure from tert-butyl groups. Tert-butyl groups are well known for the steric pressure they exert, and this serves as justification of the source of the specificity in this template synthesis. Assuming that both the addition of P-Si to the aldehyde moieties is sequential and the aldehyde oxygens remain attached to the metal center (Fig. S.1a), a rational, stereospecific reaction can be envisioned. Following the first addition of $\mathrm{P}-\mathrm{Si}$ across one of the carbonyl moieties, a steric umbrella is formed from the resultant di-tert-butyl-phosphine, effectively blocking off a same-side attack (Fig. S.1b), which results in the observed diastereochemistry of the product following the addition of the $2^{\text {nd }}$ equivalent of $\mathrm{P}-\mathrm{Si}$ to the sterically unencumbered side of the half-substituted molecule (Fig. S.1c).<smiles></smiles><smiles>C[13CH3]</smiles><smiles></smiles>

A).

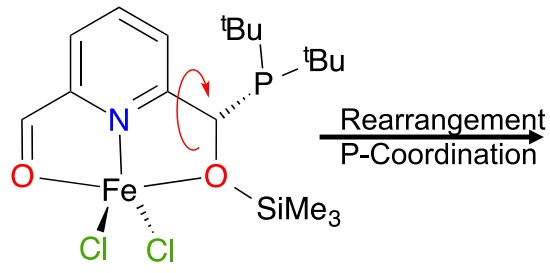<smiles></smiles>

\section{Steric Pressure}

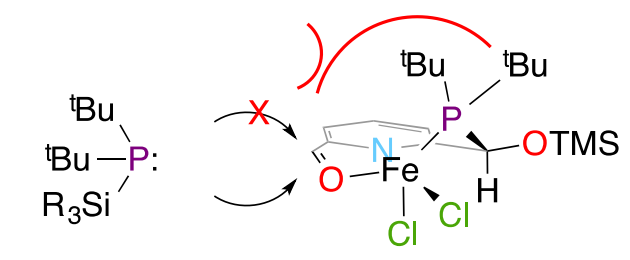

B).

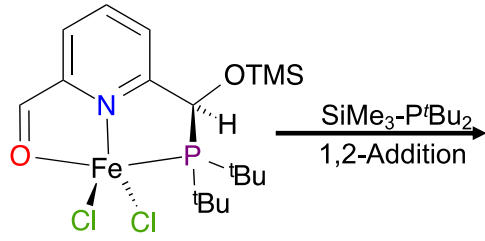

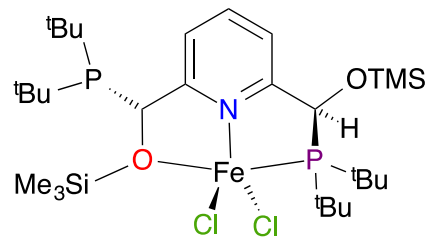

C).

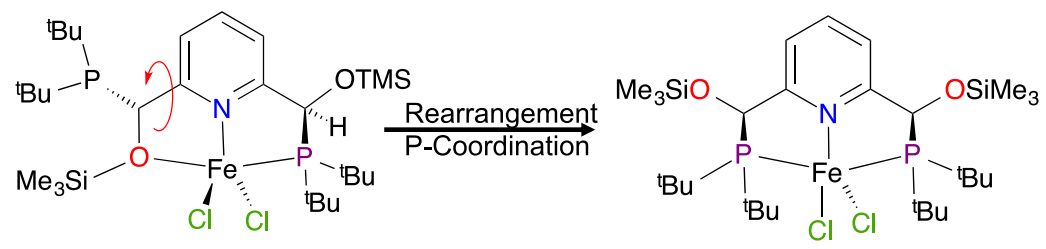

Figure S.1. Proposed rationale for the observed diastereoselectivity using $\mathrm{FeCl}_{2}$ as the example. A) The first P-Si addition yields a half-substituted ligand following phosphorus coordination to the iron; B) The steric hindrance of tert-butyl groups can block off one side of the molecule; C) The second addition of P-Si, followed by rearrangement, gives the observed product. 


\section{Supplementary Data}

\subsection{NMR Data.}

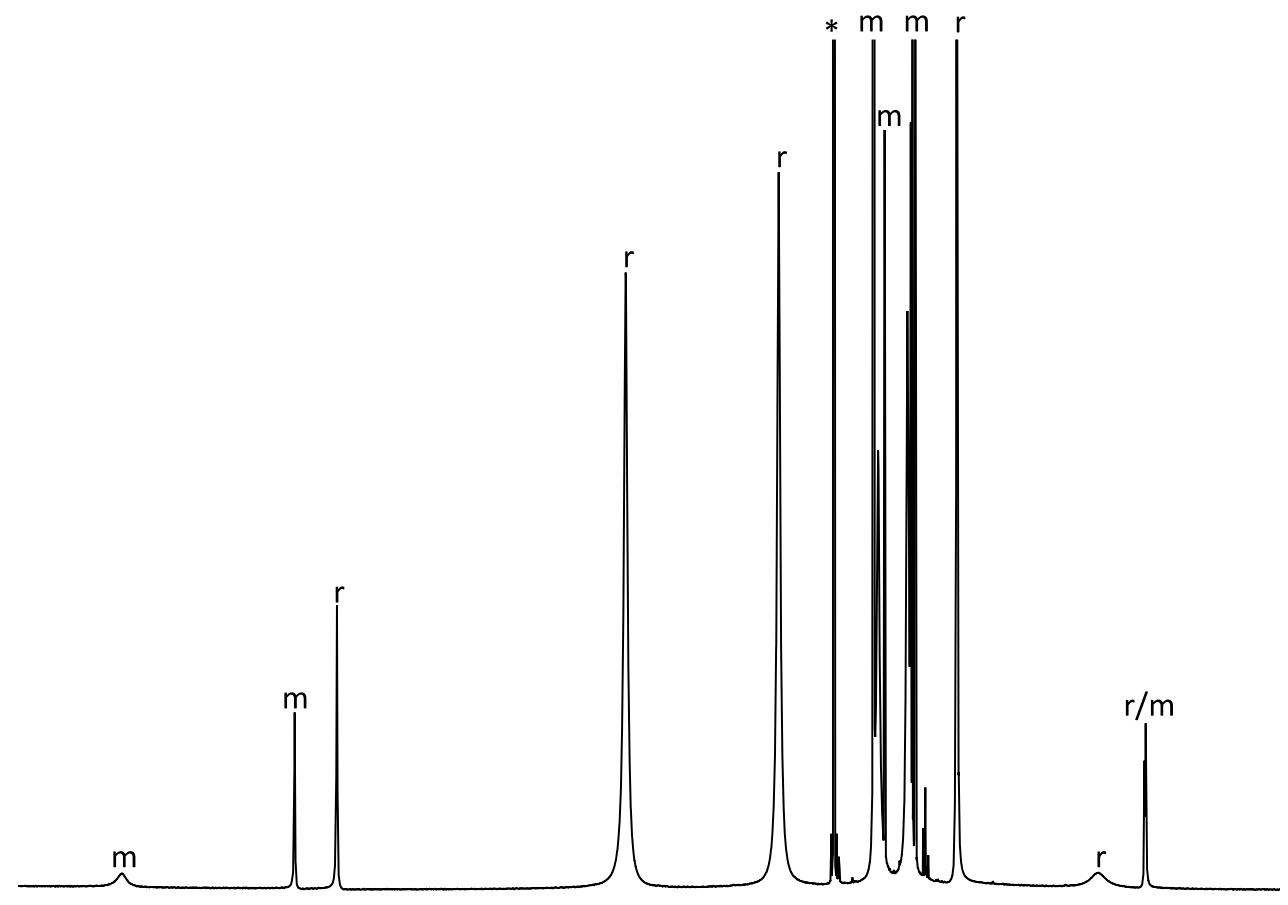

Figure S.2. ${ }^{1} \mathrm{H}$ NMR spectrum in benzene- $d_{6}$ of the crude reaction product of $\mathbf{2}-\boldsymbol{r} / \boldsymbol{m}$ from the reaction of ${ }^{(\mathrm{OTMS})} \mathrm{PNP}^{t \mathrm{~B}}, \mathbf{1 - r} / \mathbf{m}$, with $\mathrm{FeCl}_{2}$. The labels of $\mathrm{m}$ and $\mathrm{r}$ reflect the peaks corresponding to $2-\boldsymbol{m}$ and 2-r, respectively, while * indicates solvent. 


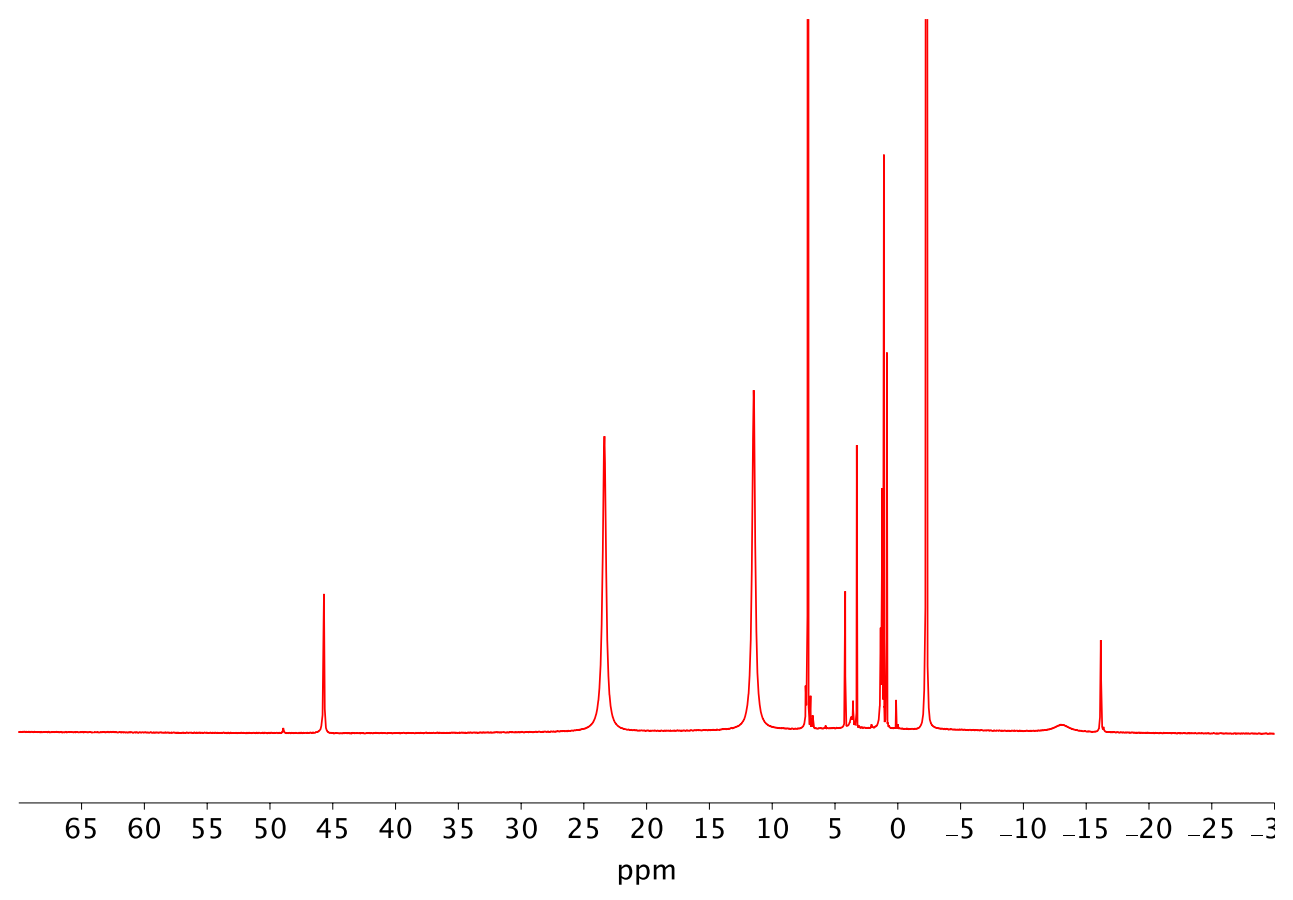

Figure S.3. ${ }^{1} \mathrm{H}$ NMR spectrum in benzene- $d_{6}$ of recrystallized $2-r / \boldsymbol{m}$ showing predominant isolation of 2-r.

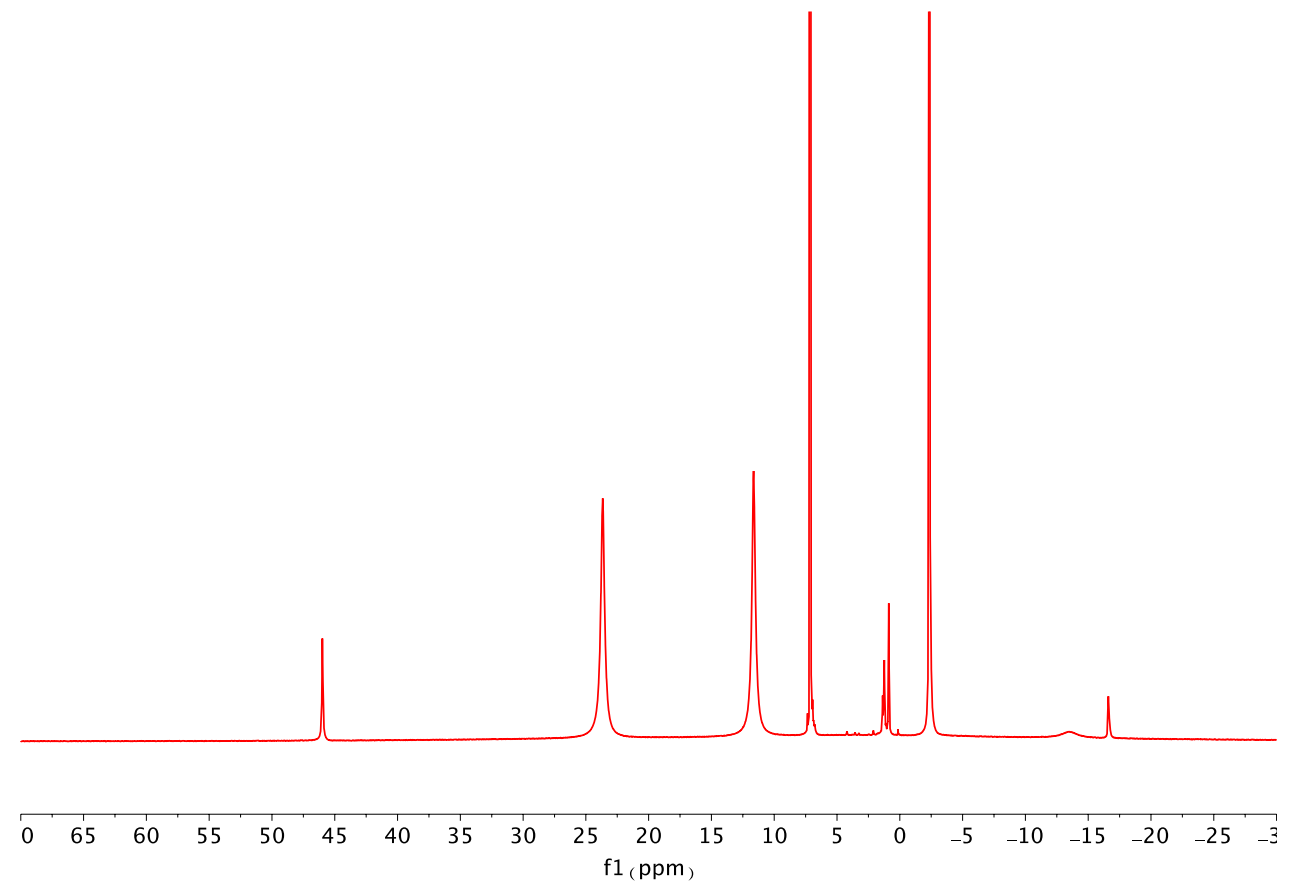

Figure S.4. ${ }^{1} \mathrm{H}$ NMR spectrum in benzene- $d_{6}$ of a second recrystallization of $2-r$ showing isolation of 2-r with little 2-m remaining. 


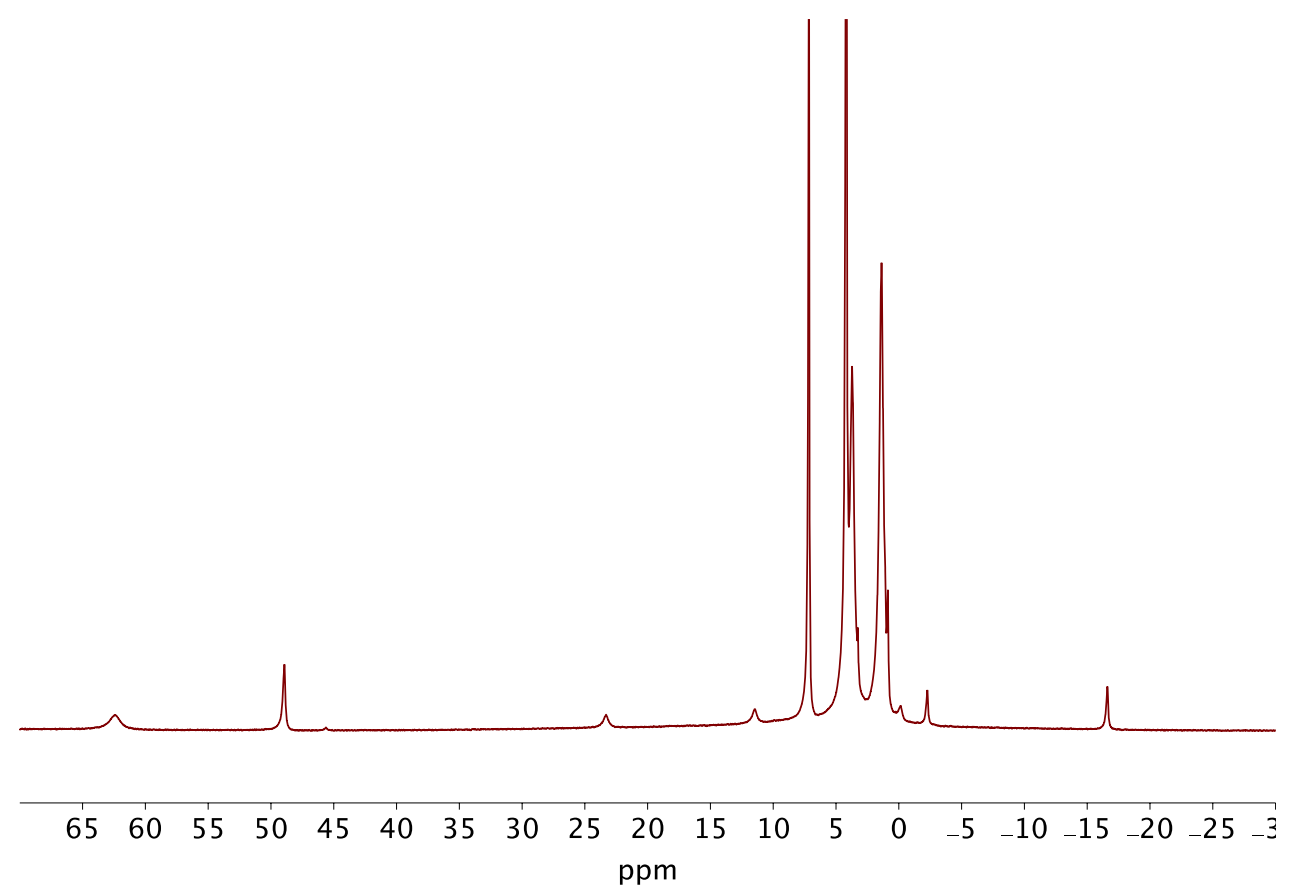

Figure S.5. ${ }^{1} \mathrm{H}$ NMR spectrum in benzene- $d_{6}$ of the crude reaction product of predominantly $\mathbf{2}-\boldsymbol{m}$ arising from the template synthesis by premixing $(\mathrm{CHO})_{2} \mathrm{Py}$ and $\mathrm{FeCl}_{2}$.

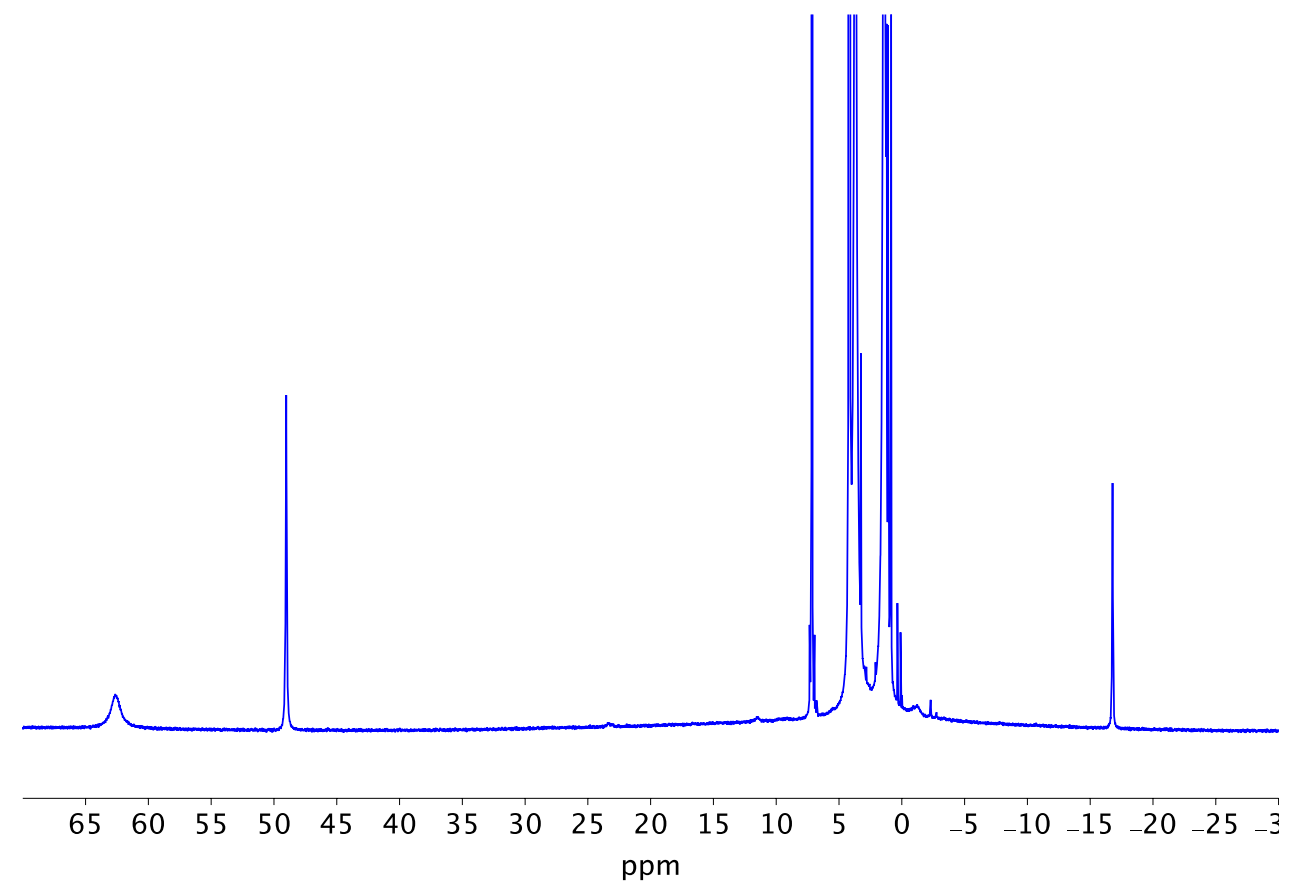

Figure S.6. ${ }^{1} \mathrm{H}$ NMR spectrum in benzene- $d_{6}$ of a recrystallization of 2- $\boldsymbol{m}$ showing isolation of 2$\boldsymbol{m}$ with little 2-r remaining. 


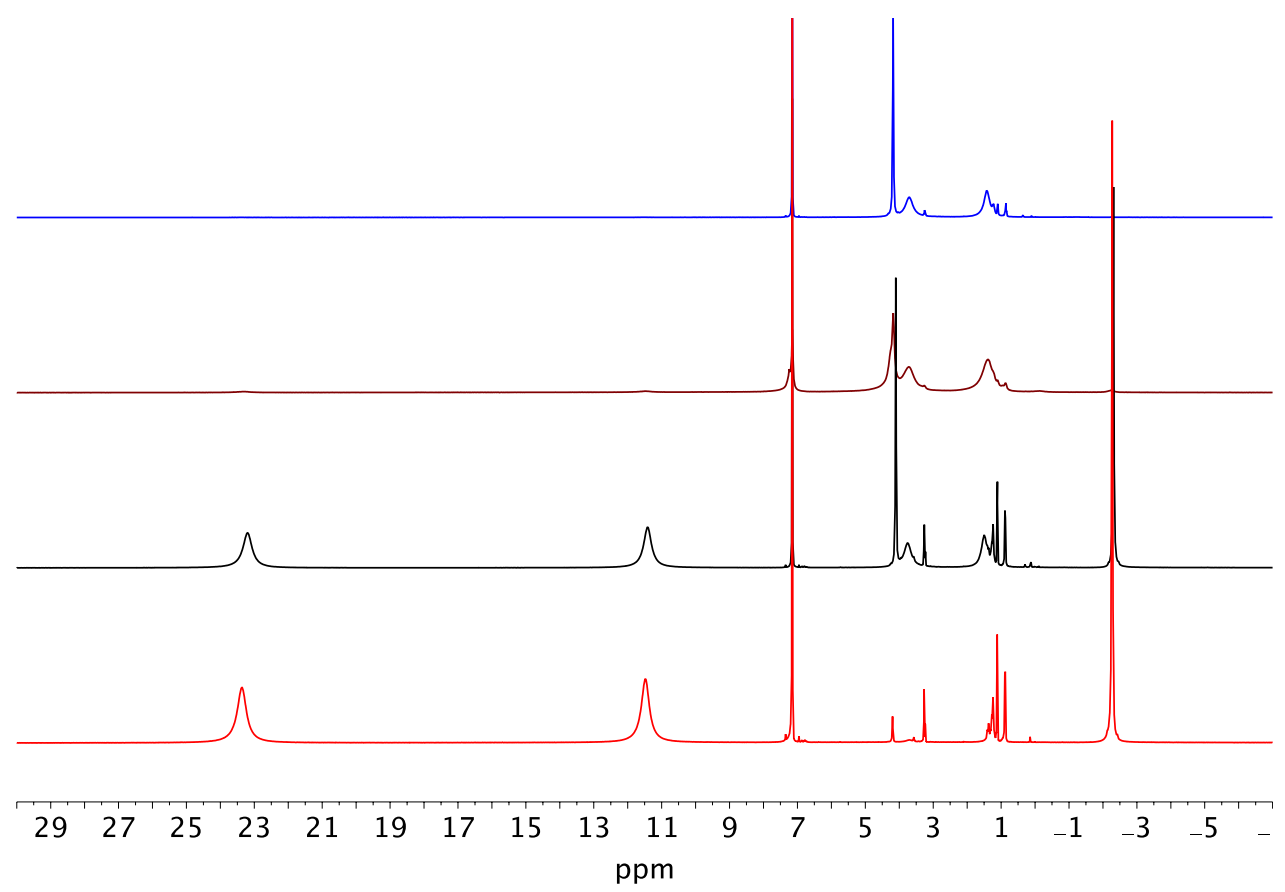

Figure S.7. Expansion of the mid-section of ${ }^{1} \mathrm{H}$ NMR spectrum in benzene- $d_{6}$ of different stages of purification of 2-r (red spectrum) and 2-m (blue spectrum).

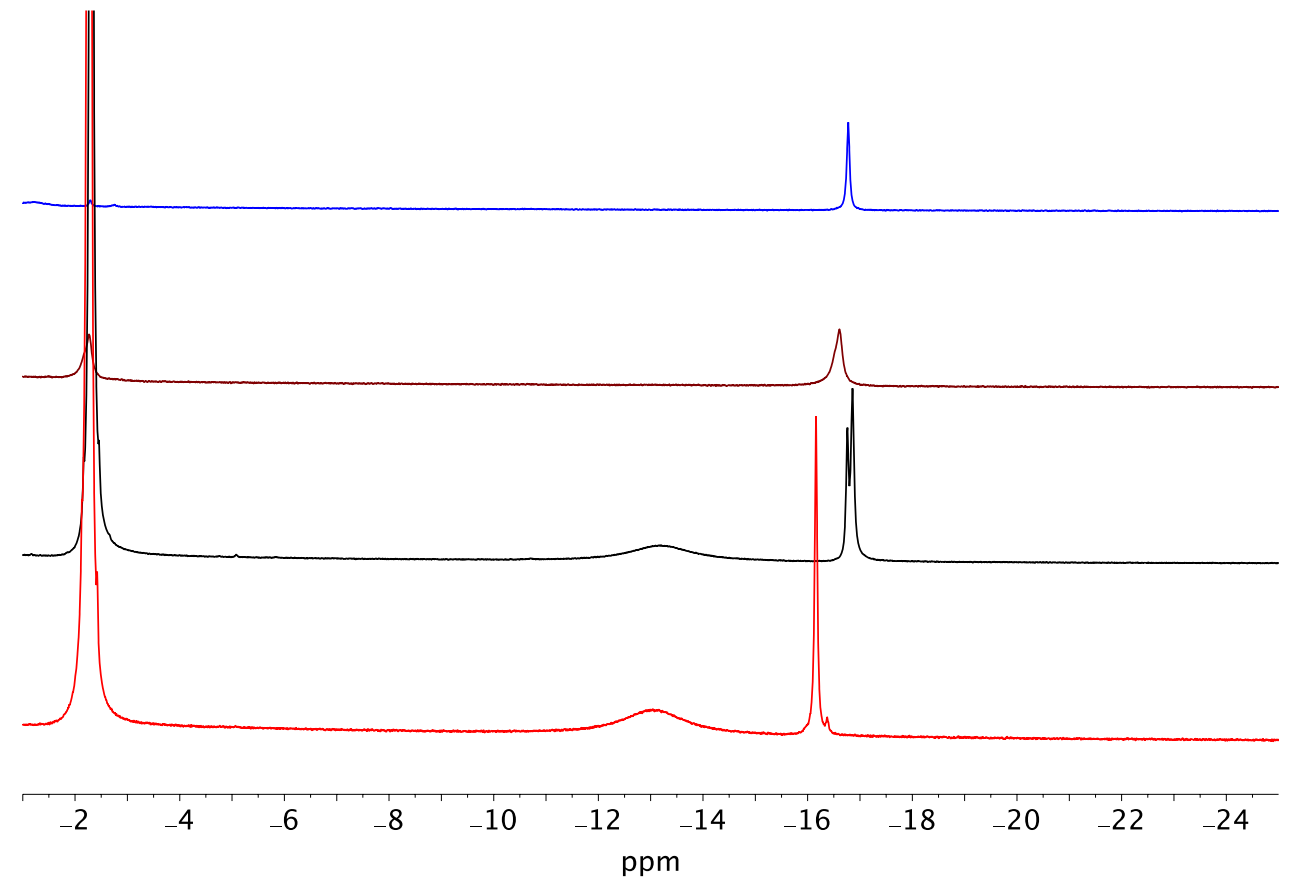

Figure S.8. Expansion of the upfield section of ${ }^{1} \mathrm{H}$ NMR spectrum in benzene- $d_{6}$ of different stages of purification of 2-r (red spectrum) and 2-m (blue spectrum). 

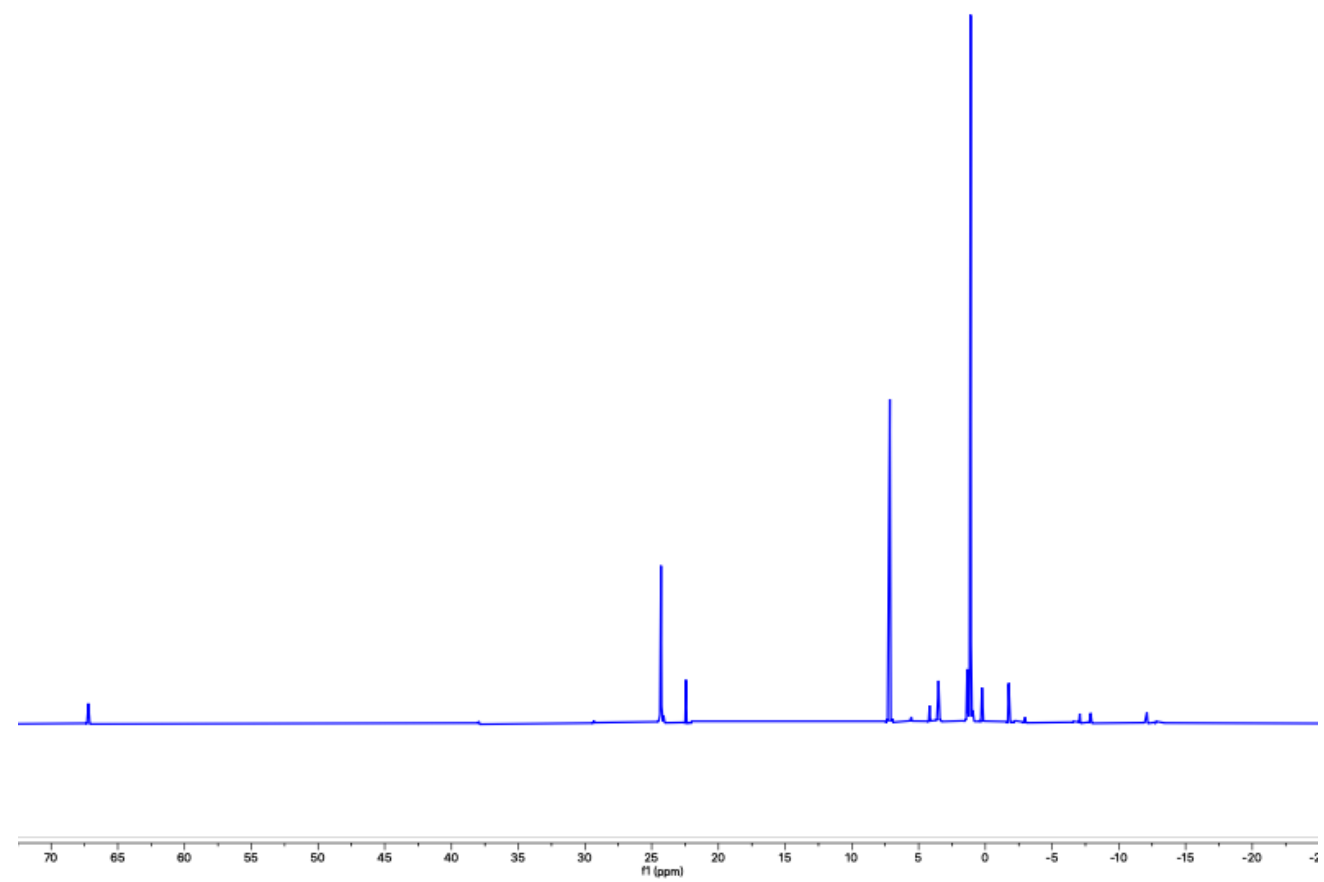

Figure S.9. ${ }^{1} \mathrm{H}$ NMR spectrum in benzene- $d_{6}$ of 3-m.

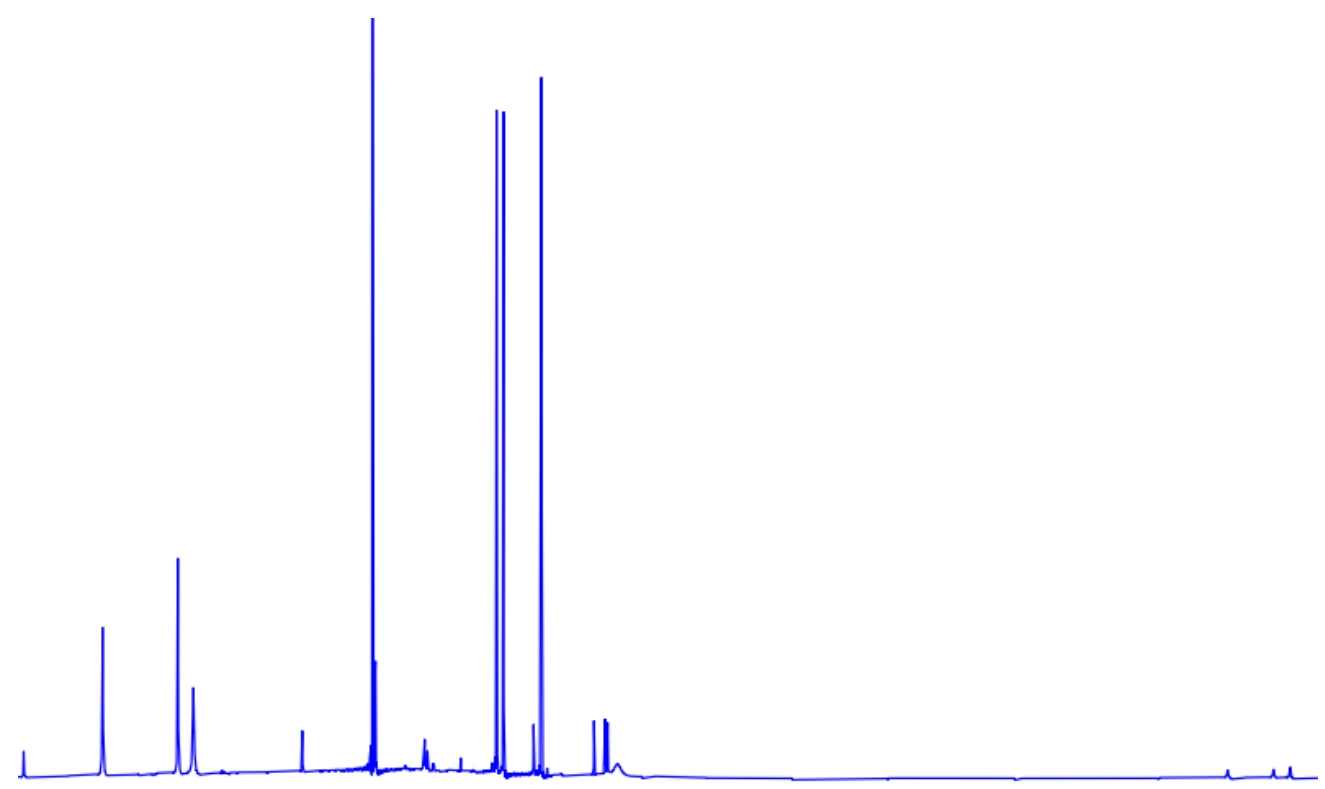

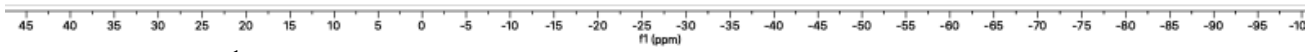

Figure S.10. ${ }^{1} \mathrm{H}$ NMR spectrum in benzene- $d_{6}$ of 4-m. 

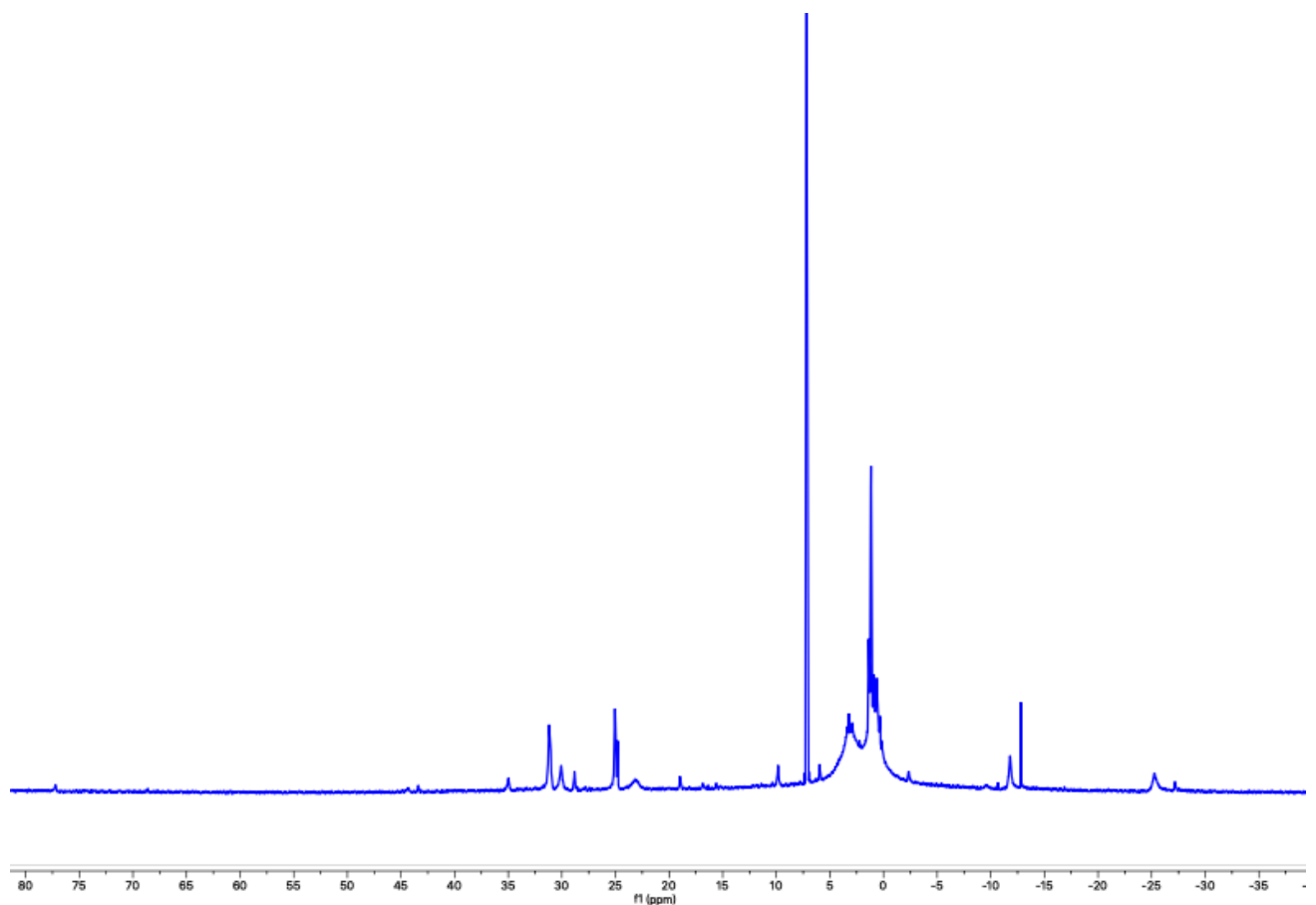

Figure S.11. ${ }^{1} \mathrm{H}$ NMR spectrum in benzene- $d_{6}$ utilizing the template synthesis with $\mathrm{UCl}_{4}$ in the absence of the stabilizing ligand, dtbpy.
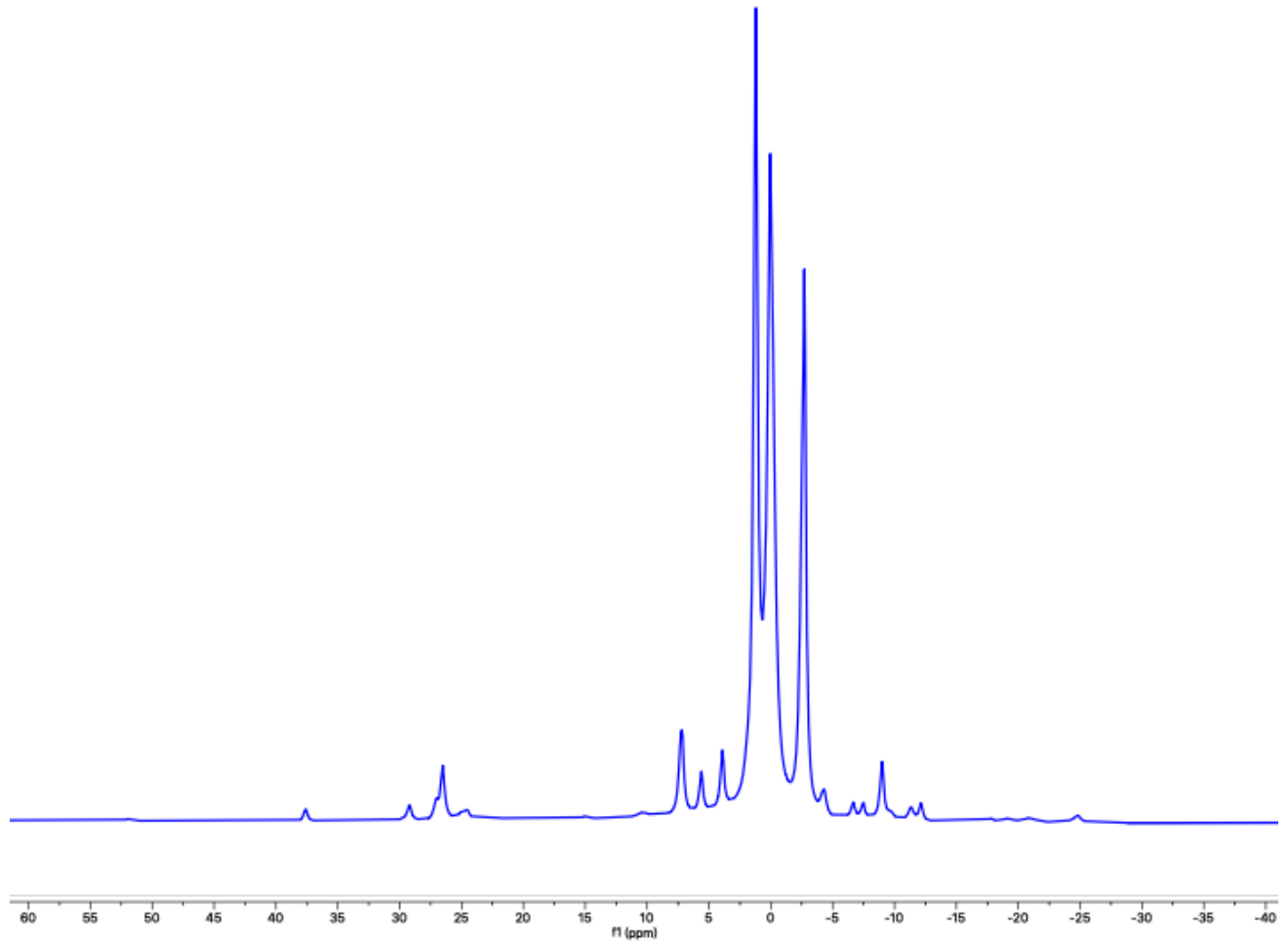

Figure S.12. ${ }^{1} \mathrm{H}$ NMR spectrum in benzene- $d_{6}$ using the pre-made ligand, $1-r / m$, for the reaction with $\mathrm{UCl}_{4}$ and dtbpy. 

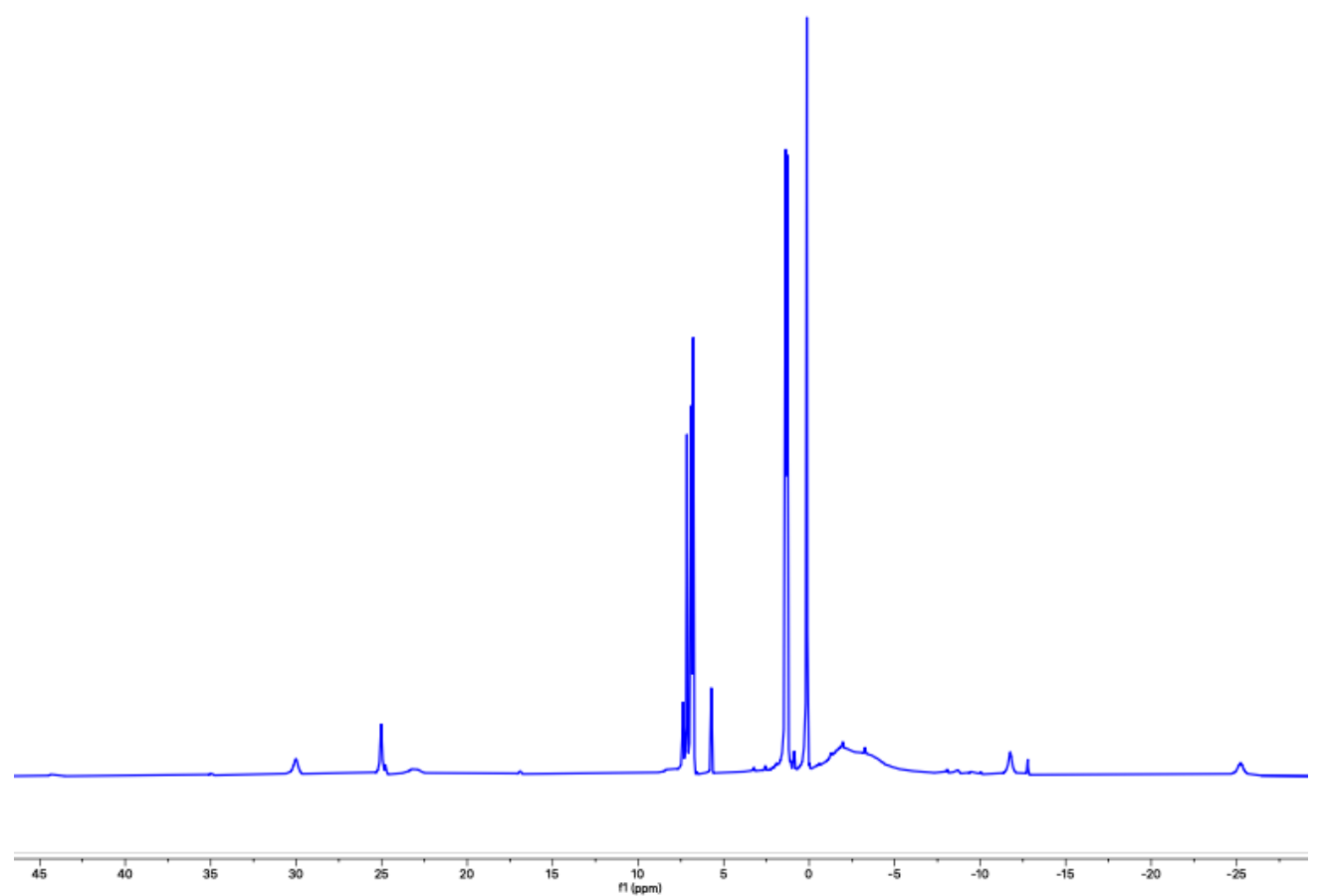

Figure S.13. ${ }^{1} \mathrm{H}$ NMR spectrum in benzene- $d_{6}$ using the pre-made ligand, $1-r / \boldsymbol{m}$, for the reaction with $\mathrm{UCl}_{4}$, in the absence of dtbpy.

\section{2. $\mathrm{UV} / \mathrm{Vis}$ data}

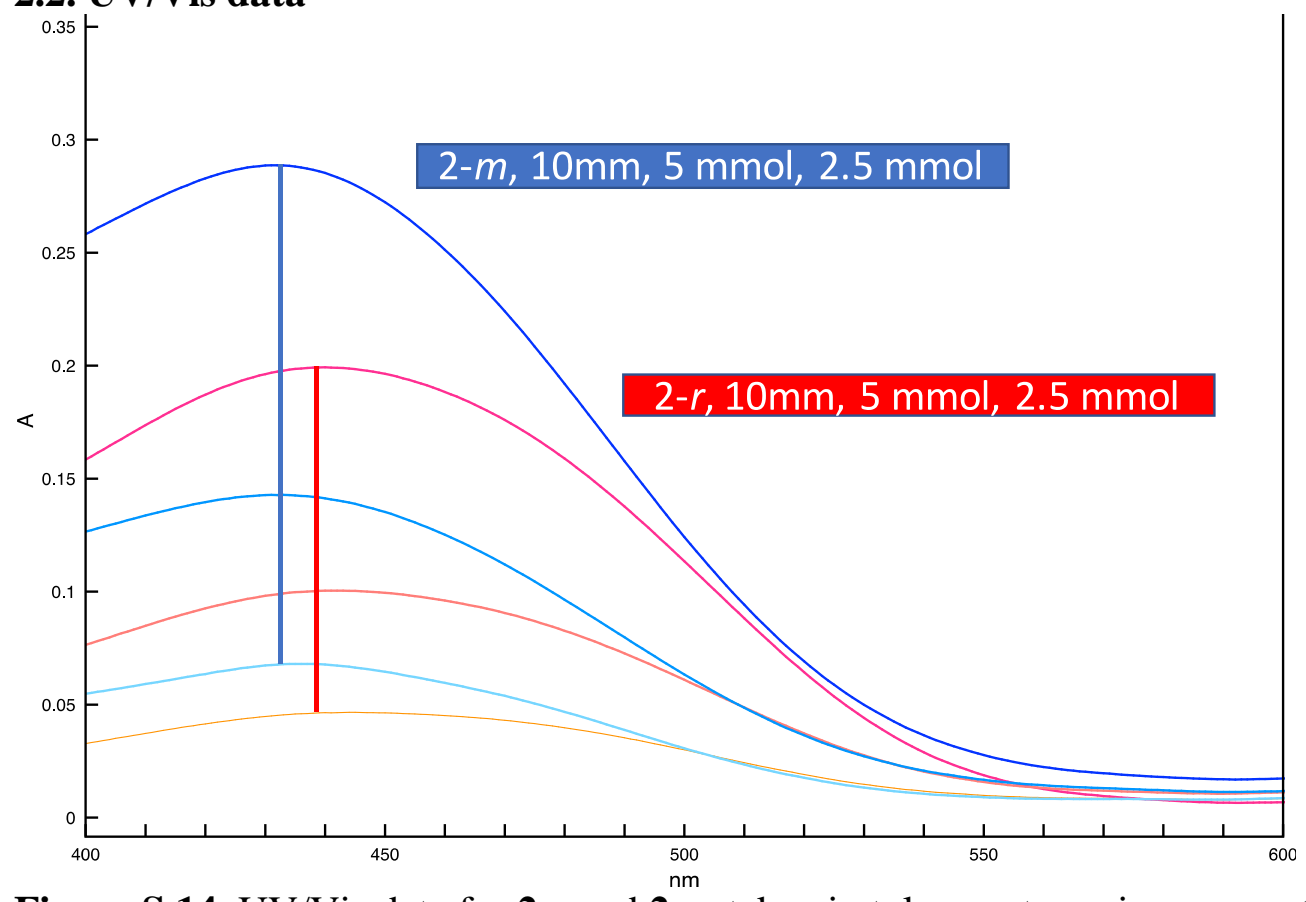

Figure S.14. UV/Vis data for 2-r and 2-m taken in toluene at varying concentrations at RT. 


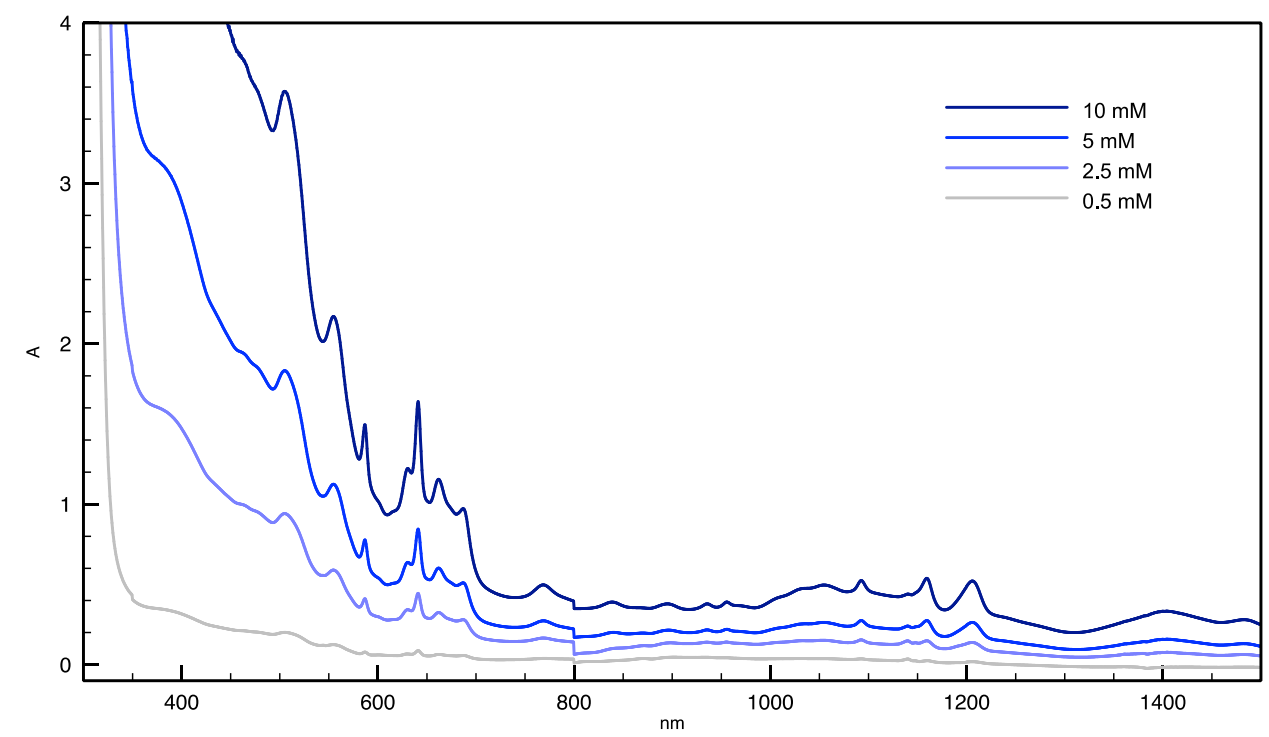

Figure S.15. UV/Vis/NIR data for 3- $\boldsymbol{m}$ taken in toluene at varying concentrations at RT.

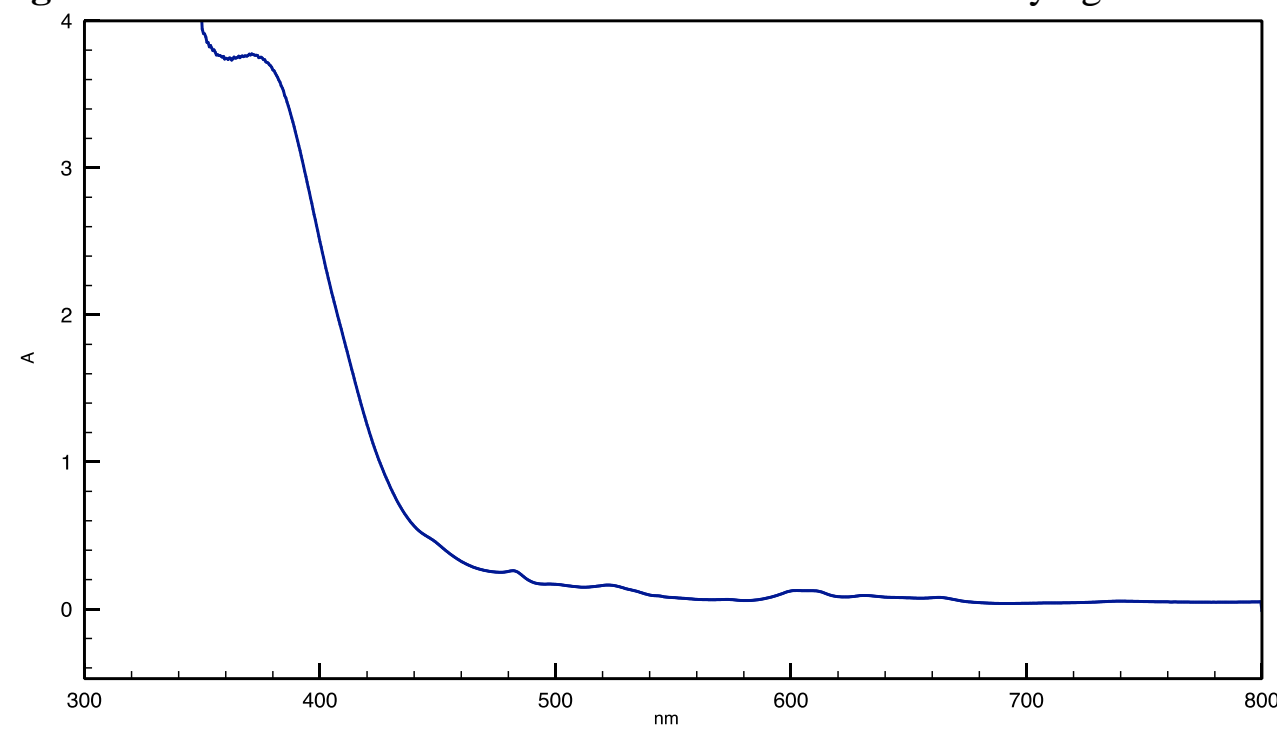

Figure S.16. UV/Vis data for the $5 \mathrm{mM}$ reaction of $\mathrm{UCl}_{4},(\mathrm{CHO})_{2} \mathrm{Py}$, and ${ }^{t} \mathrm{Bu}_{2} \mathrm{P}-\mathrm{SiMe}_{3}$, yielding a green solution, taken in toluene at RT. 


\subsection{Pictures of 3-m and 4-m.}

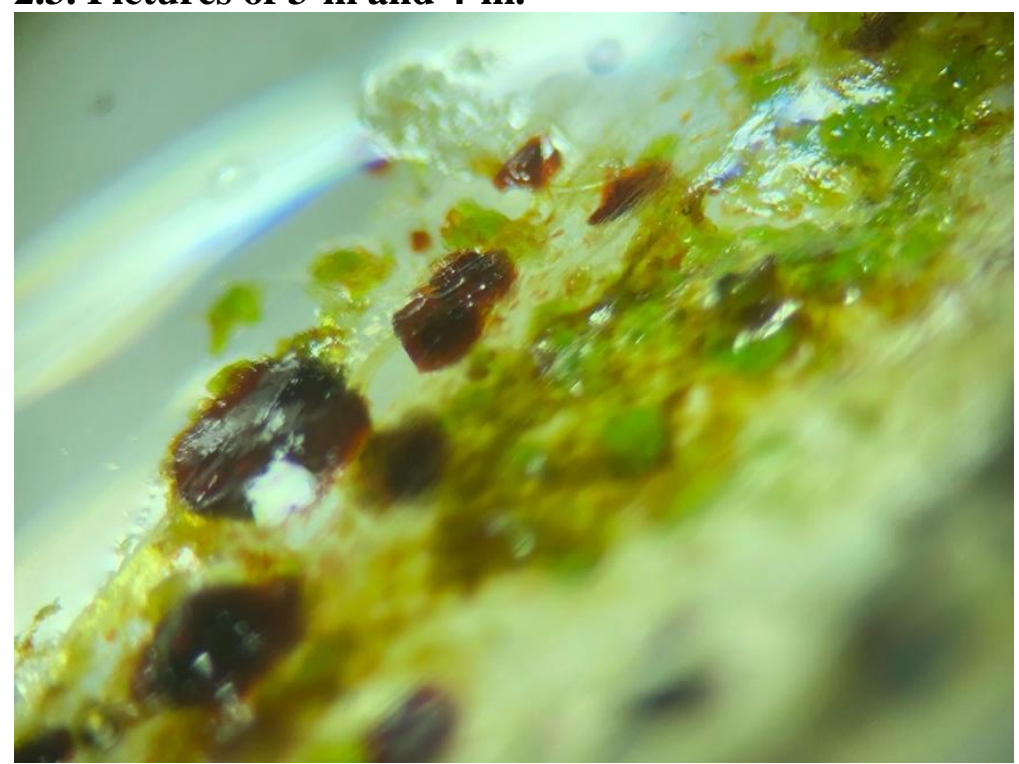

Figure S.17. Mixture of crystalline material of 3-m and 4-m. Similar solubilities of this complexes prevent the separation of the complexes in high purity.

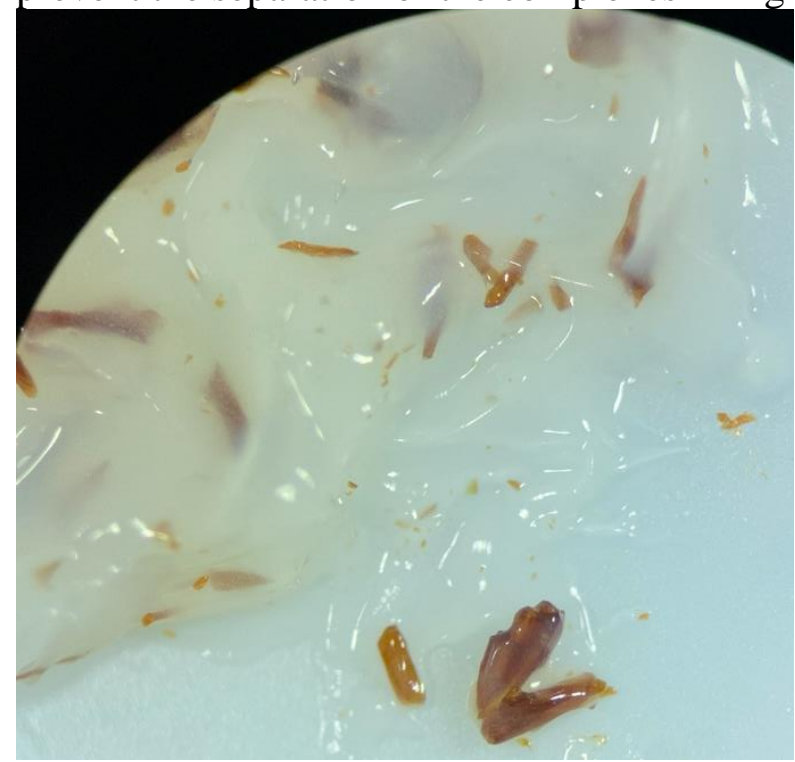

Figure S.18. Crystalline material of 3-m obtained through the selective synthesis of the complex. 


\section{Single Crystal X-ray Diffraction Data}

\subsection{CCDC Deposition}

( $\left.{ }^{(\mathrm{OTMS})} \mathrm{PNP}^{t \mathrm{Bu}}\right) \mathrm{FeCl}_{2}$ (2-r): 2081555, 2081556

( $\left.{ }^{(\mathrm{OTMS})} \mathrm{PNP}^{t \mathrm{Bu}}\right) \mathrm{FeCl}_{2}$ (2-m): 2081557

$\left.{ }^{\left({ }^{(B u 2 P}\right)} \mathrm{ONO}\right) \mathrm{UCl}_{2}$ (dtpby) (3-m): 2081558

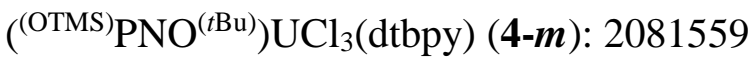

\section{2. $\left({ }^{(\mathrm{OTMS})} \mathrm{PNP}^{t \mathrm{Bu}}\right) \mathrm{FeCl}_{2}(2-r)$}

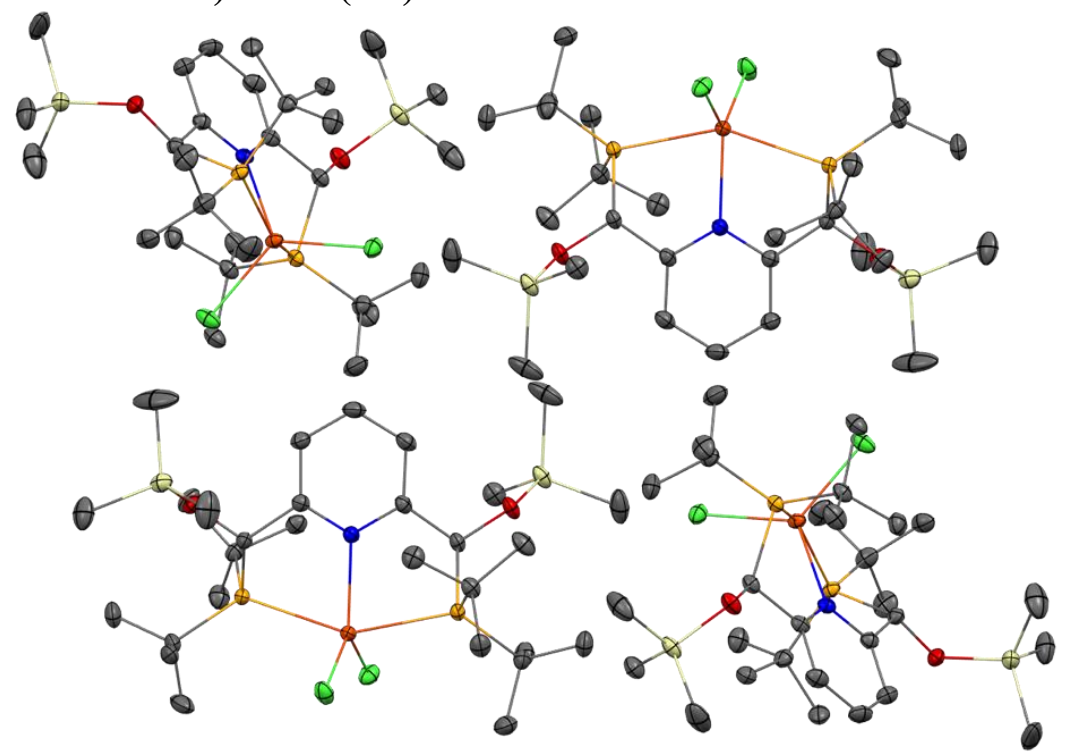

2-r $(\boldsymbol{P 2}(\mathbf{1}) / \mathbf{c})$

Identification code

Empirical formula

Formula weight

Temperature/K

Crystal system

Space group

$\mathrm{a} / \AA$

$\mathrm{b} / \AA$

c/Å

$\alpha /^{\circ}$

$\beta /^{\circ}$

$\gamma /{ }^{\circ}$

Volume $/ \AA^{3}$

Z

$\rho_{\text {calcg }} / \mathrm{cm}^{3}$
OTMSPNPFeCl2_1stCrystals

$\mathrm{C}_{29} \mathrm{H}_{59} \mathrm{Cl}_{2} \mathrm{FeNO}_{2} \mathrm{P}_{2} \mathrm{Si}_{2}$

698.64

100.15

monoclinic

$\mathrm{P} 2{ }_{1} / \mathrm{c}$

14.574(4)

14.968(4)

$17.843(5)$

90

93.778(3)

90

3883.9(18)

4

1.195 
$\mu / \mathrm{mm}^{-1}$

$\mathrm{F}(000)$

Crystal size/ $/ \mathrm{mm}^{3}$

Radiation

Index ranges

Reflections collected

Independent reflections

Data/restraints/parameters

Goodness-of-fit on $\mathrm{F}^{2}$

Final R indexes $[\mathrm{I}>=2 \sigma(\mathrm{I})]$

Final $\mathrm{R}$ indexes [all data]

Largest diff. peak/hole / e $\AA^{-3} 0.56 /-0.26$

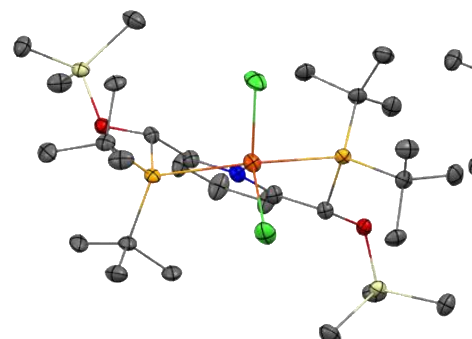

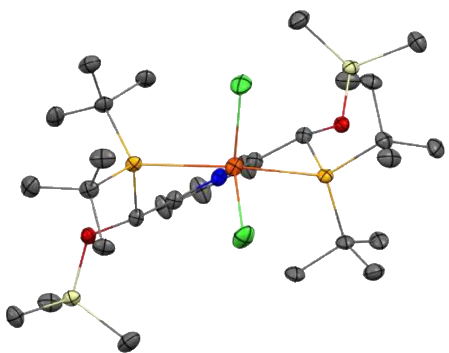

2-r (Fdd2)

Identification code

Empirical formula

Formula weight

Temperature/K

Crystal system

Space group

$\mathrm{a} / \AA$

$\mathrm{b} / \AA$

$\mathrm{c} / \AA$

$\alpha /{ }^{\circ}$

$\beta /^{\circ}$

$\gamma /{ }^{\circ}$

Volume $/ \AA^{3}$

Z
0.694

1496.0

$\operatorname{MoK} \alpha(\lambda=0.71073)$
$0.45 \times 0.45 \times 0.38$

5.206 to 56.564

$-19 \leq \mathrm{h} \leq 19,-19 \leq \mathrm{k} \leq 19,-23 \leq 1 \leq 23$

44921

$9601\left[\mathrm{R}_{\text {int }}=0.0593, \mathrm{R}_{\text {sigma }}=0.0441\right]$

9601/0/370

1.025

$\mathrm{R}_{1}=0.0312, \mathrm{wR}_{2}=0.0800$

$\mathrm{R}_{1}=0.0354, \mathrm{wR}_{2}=0.0828$

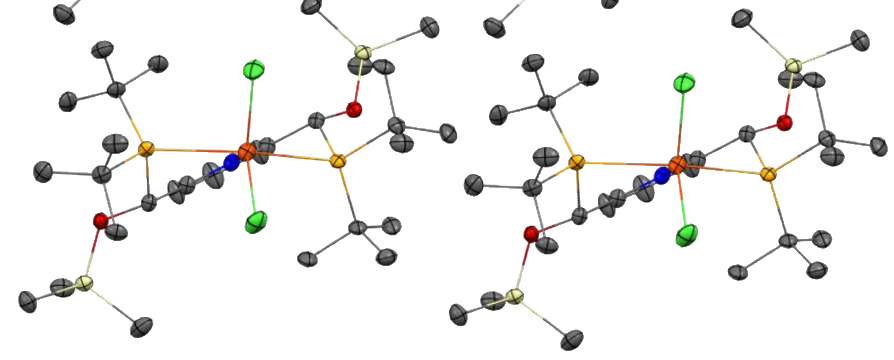

sttsts

$\mathrm{C}_{29} \mathrm{H}_{59} \mathrm{Cl}_{2} \mathrm{FeNO}_{2} \mathrm{P}_{2} \mathrm{Si}_{2}$

698.64

104.26

orthorhombic

Fdd2

23.9117(10)

$33.2588(17)$

$9.5495(5)$

90

90

90

7594.5(6)

8 


\begin{tabular}{|c|c|}
\hline$\rho_{\text {calc }} \mathrm{g} / \mathrm{cm}^{3}$ & 1.222 \\
\hline$\mu / \mathrm{mm}^{-1}$ & 0.710 \\
\hline $\mathrm{F}(000)$ & 2992.0 \\
\hline Crystal size $/ \mathrm{mm}^{3}$ & $? \times ? \times ?$ \\
\hline Radiation & $\operatorname{MoK} \alpha(\lambda=0.71073)$ \\
\hline \multicolumn{2}{|c|}{$2 \Theta$ range for data collection $/{ }^{\circ} 4.754$ to 55.886} \\
\hline Index ranges & $-31 \leq \mathrm{h} \leq 31,-43 \leq \mathrm{k} \leq 43,-12 \leq 1 \leq 12$ \\
\hline Reflections collected & 32704 \\
\hline Independent reflections & $4553\left[\mathrm{R}_{\text {int }}=0.0285, \mathrm{R}_{\text {sigma }}=0.0225\right]$ \\
\hline Data/restraints/parameters & $4553 / 1 / 187$ \\
\hline Goodness-of-fit on $\mathrm{F}^{2}$ & 1.124 \\
\hline Final $\mathrm{R}$ indexes $[\mathrm{I}>=2 \sigma(\mathrm{I})]$ & $\mathrm{R}_{1}=0.0254, \mathrm{w} \mathrm{R}_{2}=0.0619$ \\
\hline Final $\mathrm{R}$ indexes [all data] & $\mathrm{R}_{1}=0.0273, \mathrm{w} \mathrm{R}_{2}=0.0628$ \\
\hline \multicolumn{2}{|c|}{ Largest diff. peak/hole / e $\AA^{-3} 0.43 /-0.27$} \\
\hline Flack parameter & $0.003(4)$ \\
\hline
\end{tabular}

\section{3. $\left({ }^{(\mathrm{OTMS})} \mathrm{PNP}^{t \mathrm{Bu}}\right) \mathrm{FeCl}_{2}(2-m)$}

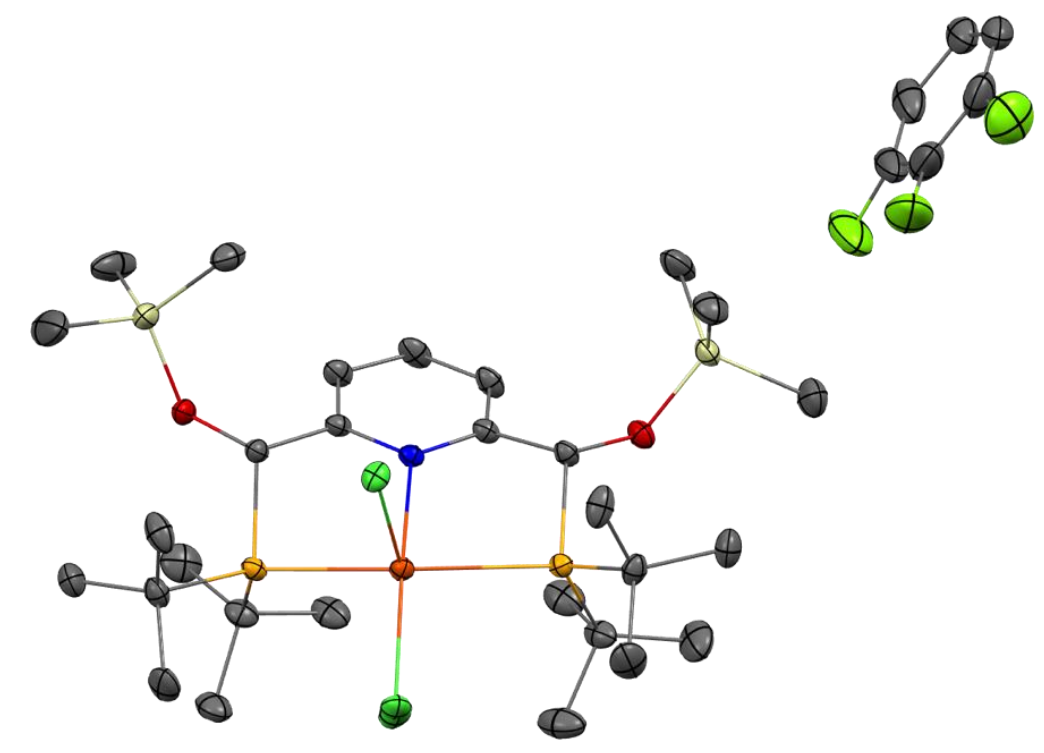

\section{2-m}

Identification code

meso_OTMSPNPFeCl2

Empirical formula

$\mathrm{C}_{35} \mathrm{H}_{64} \mathrm{Cl}_{2} \mathrm{FFeNO}_{2} \mathrm{P}_{2} \mathrm{Si}_{2}$

Formula weight

794.74

Temperature/K

100(2)

Crystal system

monoclinic

Space group

$\mathrm{P} 2{ }_{1} / \mathrm{n}$

$\mathrm{a} / \AA$

$11.248(2)$

$\mathrm{b} / \AA$

24.939(5) 


\begin{tabular}{|c|c|}
\hline$c / \AA$ & $15.265(3)$ \\
\hline$\alpha /^{\circ}$ & 90 \\
\hline$\beta /^{\circ}$ & $94.905(2)$ \\
\hline$\gamma /{ }^{\circ}$ & 90 \\
\hline Volume $/ \AA^{3}$ & 4266.4(15) \\
\hline $\mathrm{Z}$ & 4 \\
\hline$\rho_{\text {calc }} \mathrm{g} / \mathrm{cm}^{3}$ & 1.237 \\
\hline$\mu / \mathrm{mm}^{-1}$ & 0.644 \\
\hline $\mathrm{F}(000)$ & 1696.0 \\
\hline Crystal size $/ \mathrm{mm}^{3}$ & $0.45 \times 0.4 \times 0.35$ \\
\hline Radiation & $\operatorname{MoK} \alpha(\lambda=0.71073)$ \\
\hline \multicolumn{2}{|c|}{$2 \Theta$ range for data collection $/{ }^{\circ} 6.788$ to 57.09} \\
\hline Index ranges & $-15 \leq \mathrm{h} \leq 14,-33 \leq \mathrm{k} \leq 33,-20 \leq 1 \leq 20$ \\
\hline Reflections collected & 49593 \\
\hline Independent reflections & $10804\left[R_{\text {int }}=0.0292, R_{\text {sigma }}=0.0243\right]$ \\
\hline Data/restraints/parameters & $10804 / 1 / 464$ \\
\hline Goodness-of-fit on $\mathrm{F}^{2}$ & 1.038 \\
\hline Final $\mathrm{R}$ indexes $[\mathrm{I}>=2 \sigma(\mathrm{I})]$ & $\mathrm{R}_{1}=0.0351, \mathrm{wR}_{2}=0.0852$ \\
\hline Final $\mathrm{R}$ indexes [all data] & $\mathrm{R}_{1}=0.0422, \mathrm{wR}_{2}=0.0894$ \\
\hline Largest diff. peak/hole / e $\AA$ & $0.97 /-0.32$ \\
\hline
\end{tabular}

\section{4. $\left(^{\left({ }^{(O T M S}\right)} \mathrm{ONO}\right) \mathrm{UCl}_{2}$ (dtbpy) (3-m)}

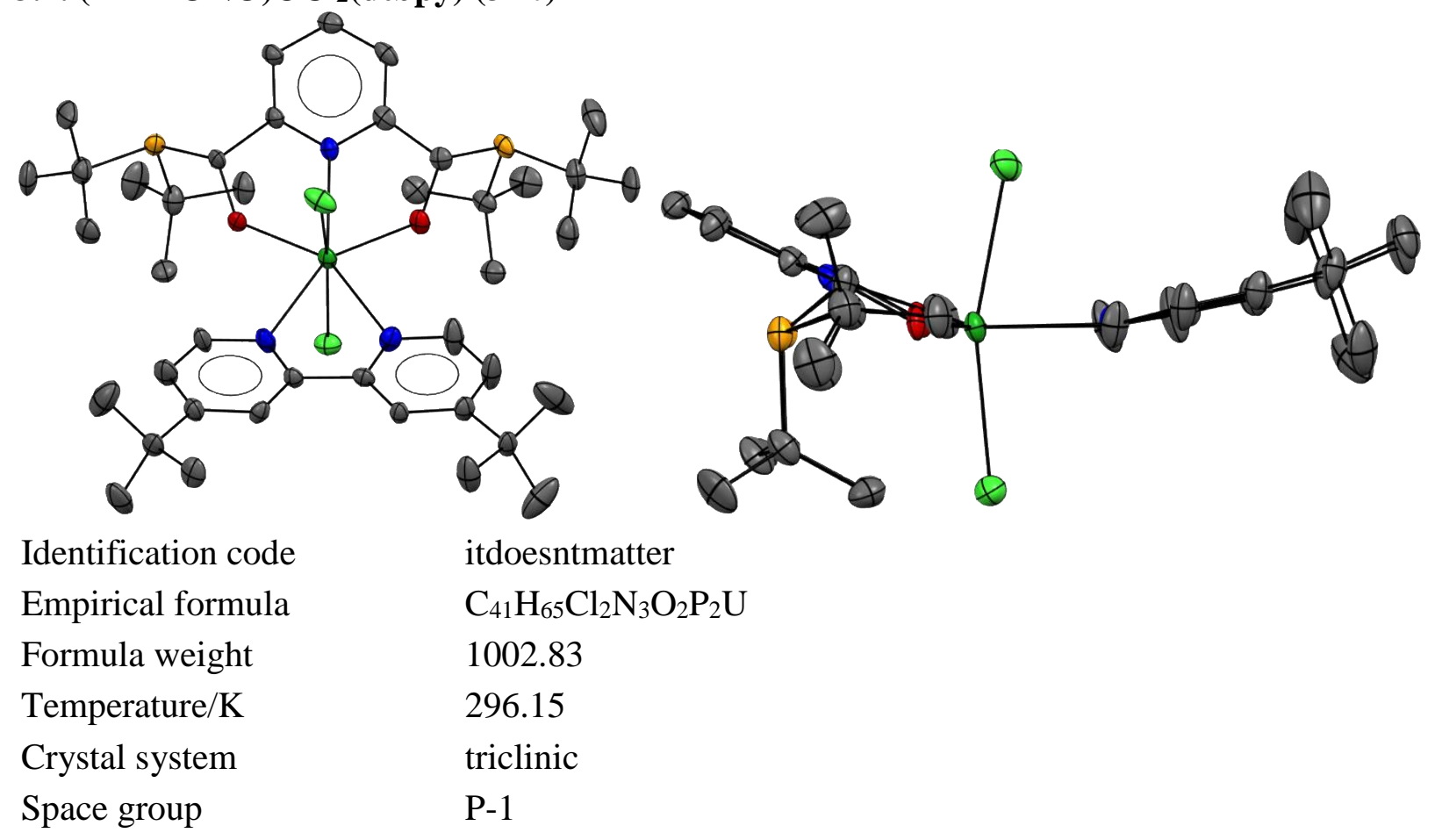




\begin{tabular}{|c|c|}
\hline $\mathrm{a} / \AA$ & $14.859(6)$ \\
\hline $\mathrm{b} / \AA$ & $15.233(7)$ \\
\hline $\mathrm{c} / \AA$ & $16.028(7)$ \\
\hline$\alpha /^{\circ}$ & $76.389(4)$ \\
\hline$\beta /{ }^{\circ}$ & $69.539(4)$ \\
\hline$\gamma /{ }^{\circ}$ & $72.775(4)$ \\
\hline Volume $/ \AA^{3}$ & $3211(2)$ \\
\hline $\mathrm{Z}$ & 2 \\
\hline$\rho_{\text {calc }} \mathrm{g} / \mathrm{cm}^{3}$ & 1.037 \\
\hline$\mu / \mathrm{mm}^{-1}$ & 2.685 \\
\hline $\mathrm{F}(000)$ & 1008.0 \\
\hline Crystal size $/ \mathrm{mm}^{3}$ & $0.546 \times 0.14 \times 0.1$ \\
\hline Radiation & $\operatorname{MoK} \alpha(\lambda=0.71073)$ \\
\hline \multicolumn{2}{|c|}{$2 \Theta$ range for data collection $/{ }^{\circ} 2.742$ to 52.044} \\
\hline Index ranges & $-18 \leq \mathrm{h} \leq 18,-18 \leq \mathrm{k} \leq 18,-19 \leq 1 \leq 19$ \\
\hline Reflections collected & 30320 \\
\hline Independent reflections & $12477\left[\mathrm{R}_{\text {int }}=0.0416, \mathrm{R}_{\text {sigma }}=0.0587\right]$ \\
\hline Data/restraints/parameters & $12477 / 0 / 479$ \\
\hline Goodness-of-fit on $\mathrm{F}^{2}$ & 1.069 \\
\hline Final $R$ indexes $[\mathrm{I}>=2 \sigma(\mathrm{I})]$ & $\mathrm{R}_{1}=0.0551, \mathrm{wR}_{2}=0.1284$ \\
\hline Final $\mathrm{R}$ indexes [all data] & $\mathrm{R}_{1}=0.0624, \mathrm{wR}_{2}=0.1310$ \\
\hline Largest diff. peak/hole / e $\AA^{-3}$ & $3.77 /-1.81$ \\
\hline
\end{tabular}

3.5. $\left({ }^{(\mathrm{OTMS})} \mathrm{PNO}^{t \mathrm{Bu}}\right) \mathrm{UCl}_{3}(\mathrm{dtbpy})(4-m)$

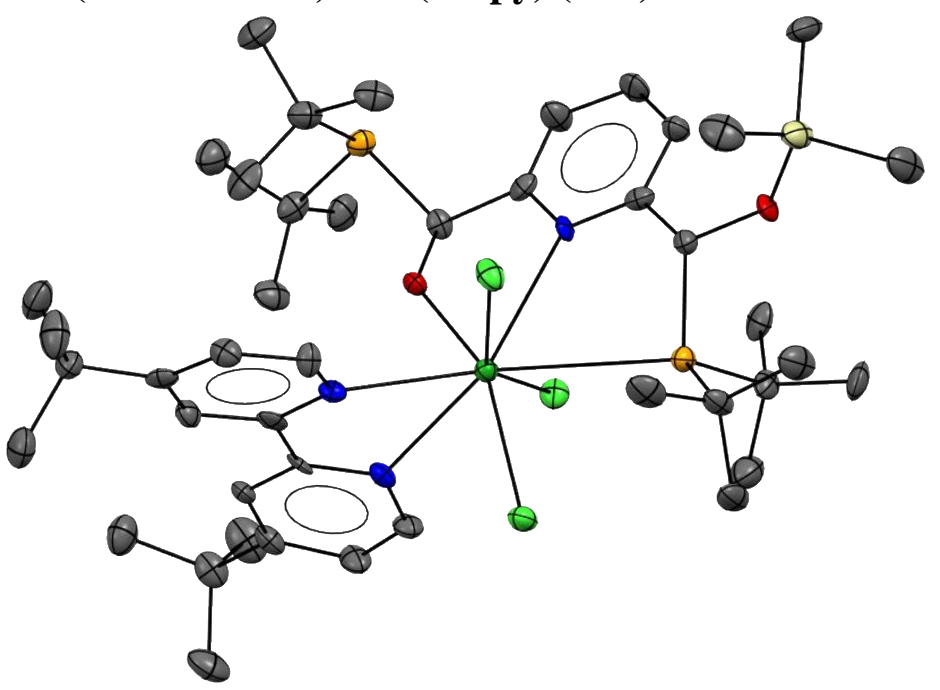

Identification code

bestUbipyPyCHO 


\begin{tabular}{|c|c|}
\hline Empirical formula & $\mathrm{C}_{44} \mathrm{H}_{74} \mathrm{Cl}_{3} \mathrm{~N}_{3} \mathrm{O}_{2} \mathrm{P}_{2} \mathrm{SiU}$ \\
\hline Formula weight & 1111.47 \\
\hline Temperature/K & 100.15 \\
\hline Crystal system & monoclinic \\
\hline Space group & $\mathrm{P} 2{ }_{1} / \mathrm{n}$ \\
\hline $\mathrm{a} / \AA ̊ \AA$ & $14.713(16)$ \\
\hline $\mathrm{b} / \AA$ & $25.56(3)$ \\
\hline $\mathrm{c} / \AA$ & $14.775(16)$ \\
\hline$\alpha /{ }^{\circ}$ & 90 \\
\hline$\beta /{ }^{\circ}$ & $94.096(14)$ \\
\hline$\gamma /{ }^{\circ}$ & 90 \\
\hline Volume $/ \AA^{3}$ & $5541(11)$ \\
\hline $\mathrm{Z}$ & 4 \\
\hline$\rho_{\text {calc }} \mathrm{g} / \mathrm{cm}^{3}$ & 1.332 \\
\hline$\mu / \mathrm{mm}^{-1}$ & 3.186 \\
\hline $\mathrm{F}(000)$ & 2248.0 \\
\hline Crystal size $/ \mathrm{mm}^{3}$ & $0.25 \times 0.1 \times 0.08$ \\
\hline Radiation & $\operatorname{MoK} \alpha(\lambda=0.71073)$ \\
\hline \multicolumn{2}{|c|}{$2 \Theta$ range for data collection $/{ }^{\circ} 3.188$ to 53.27} \\
\hline Index ranges & $-18 \leq \mathrm{h} \leq 18,-31 \leq \mathrm{k} \leq 31,-18 \leq 1 \leq 18$ \\
\hline Reflections collected & 36832 \\
\hline Independent reflections & $11484\left[\mathrm{R}_{\mathrm{int}}=0.1031, \mathrm{R}_{\text {sigma }}=0.1219\right]$ \\
\hline Data/restraints/parameters & $11484 / 0 / 527$ \\
\hline Goodness-of-fit on $\mathrm{F}^{2}$ & 0.980 \\
\hline Final $R$ indexes $[\mathrm{I}>=2 \sigma(\mathrm{I})]$ & $\mathrm{R}_{1}=0.0530, \mathrm{wR}_{2}=0.0839$ \\
\hline Final $\mathrm{R}$ indexes [all data] & $\mathrm{R}_{1}=0.0960, \mathrm{wR}_{2}=0.0973$ \\
\hline Largest diff. peak/hole / e $\AA^{-}$ & $1.52 /-1.40$ \\
\hline
\end{tabular}




\section{References}

1. Kiplinger, J. L.; Morris, D. E.; Scott, B. L.; Burns, C. J., Convenient synthesis, structure, and reactivity of $\left(\mathrm{C}_{5} \mathrm{Me}_{5}\right) \mathrm{U}\left(\mathrm{CH}_{2} \mathrm{C}_{6} \mathrm{H}_{5}\right)_{3}$ : a simple strategy for the preparation of monopentamethylcyclopentadienyl uranium(IV) complexes. Organometallics 2002, 21 (26), 5978-5982.

2. Radcliffe, J. E.; Batsanov, A. S.; Smith, D. M.; Scott, J. A.; Dyer, P. W.; Hanton, M. J., Phosphanyl methanimine (PCN) ligands for the selective trimerization/tetramerization of ethylene with chromium. ACS Catal. 2015, 5 (12), 7095-7098.

3. Bruker Instrument Service, Version 2010.1.0.0; Bruker AXS Inc.:Madison, WI, USA, 2010.

4. a) SAINT Plus, Data Reduction Software, Version 7.68A; Bruker AXS Inc.: Madison, WI, USA, 2009; b) G. M. Sheldrick, Acta Crystallogr., Sect. A: Found. Crystallogr. A64, 2008, 112-122.c) SADABS, Sheldrick, G.M.; University of Göttingen, Germany: 2005.

5. G. M. Sheldrick, Acta Crystallogr., Sect. A: Found. Adv. C71, 2015, 3-8; b) APEX2, Data Refinement Software, Version 2010.1-2; Bruker AXS Inc.: Madison, WI, USA, 2010.

6. Olex2 1.2 (compiled 2014.06.27 svn.r2953 for OlexSys, GUI svn.r4855; b) O. V. Dolomanov, L. J. Bourhis, R. J. Gildea, J. A. K. Howard, and H. Puschmann, J. Appl. Cryst. 2009, 42, 339-341.

7. Liu, J.; Hu, L.; Wang, L.; Chen, H.; Deng, L., An iron(II) ylide complex as a masked open-shell iron alkylidene species in its alkylidene-transfer reactions with alkenes. J. Am. Chem. Soc. 2017, 139 (10), 3876-3888.

8. Liu, Y.; Wang, L.; Deng, L., Three-coordinate iron(II) dialkenyl compound with NHC ligation: synthesis, structure, and reactivity. Organometallics 2015, 34 (17), 4401-4407.

9. Wolford, N. J.; Sergentu, D.-C.; Brennessel, W. W.; Autschbach, J.; Neidig, M. L., Homoleptic aryl complexes of uranium (IV). Angew. Chem., Int. Ed. 2019, 58 (30), 10266-10270.

10. Fortier, S.; Melot, B. C.; Wu, G.; Hayton, T. W., Homoleptic uranium(IV) alkyl complexes: synthesis and characterization. J. Am. Chem. Soc. 2009, 131 (42), 15512-15521. 